\title{
FoxO1 expression in osteoblasts regulates glucose homeostasis through regulation of osteocalcin in mice
}

\author{
Marie-Therese Rached, ${ }^{1}$ Aruna Kode, ${ }^{1}$ Barbara C. Silva, ${ }^{1}$ Dae Young Jung, ${ }^{2}$ \\ Susan Gray, ${ }^{2}$ Helena Ong, ${ }^{2}$ Ji-Hye Paik, ${ }^{3}$ Ronald A. DePinho, ${ }^{3}$ \\ Jason K. Kim, ${ }^{2,4}$ Gerard Karsenty, ${ }^{5}$ and Stavroula Kousteni ${ }^{1}$
}

\begin{abstract}
1Department of Medicine, Division of Endocrinology, College of Physicians and Surgeons, Columbia University, New York, New York, USA 2Program in Molecular Medicine, University of Massachusetts Medical School, Worcester, Massachusetts, USA. ${ }^{3}$ Department of Medical Oncology and Center for Applied Cancer Science, Dana-Farber Cancer Institute, Boston, Massachusetts, USA. ${ }^{4}$ Department of Medicine, Division of Endocrinology, Metabolism, and Diabetes, University of Massachusetts Medical School, Worcester, Massachusetts, USA. 5Department of Genetics and Development, College of Physicians and Surgeons, Columbia University, New York, New York, USA.
\end{abstract}

\begin{abstract}
Osteoblasts have recently been found to play a role in regulating glucose metabolism through secretion of osteocalcin. It is unknown, however, how this osteoblast function is regulated transcriptionally. As FoxO1 is a forkhead family transcription factor known to regulate several key aspects of glucose homeostasis, we investigated whether its expression in osteoblasts may contribute to its metabolic functions. Here we show that mice lacking Foxo1 only in osteoblasts had increased pancreatic $\beta$ cell proliferation, insulin secretion, and insulin sensitivity. The ability of osteoblast-specific FoxO1 deficiency to affect metabolic homeostasis was due to increased osteocalcin expression and decreased expression of Esp, a gene that encodes a protein responsible for decreasing the bioactivity of osteocalcin. These results indicate that FoxO1 expression in osteoblasts contributes to FoxO1 control of glucose homeostasis and identify FoxO1 as a key modulator of the ability of the skeleton to function as an endocrine organ regulating glucose metabolism.
\end{abstract}

\section{Introduction}

Insulin, a hormone whose main function is to regulate blood glucose level, is a major endocrine regulator of energy metabolism. Insulin resistance plays a fundamental role in the pathogenesis of a host of metabolic diseases, ranging from type 2 diabetes mellitus to hypertension, lipid disorders, atherosclerosis, and reproductive dysfunction (1). Given the paramount importance of insulin, its signaling pathway has been studied intensively since its receptor was identified and molecularly cloned (2). This body of work has highlighted the biological importance of FoxO1, as the major transcriptional mediator of insulin signaling in many cells, including the $\beta$ cell, the adipocyte, the hepatocyte, and the myoblast (3-8). FoxO1, which belongs to the Forkhead family of transcription factors, is a negative regulator of insulin sensitivity in $\beta$ cells, hepatocytes, and adipocytes. Loss- or gain-of-function animal models of FoxO1 have clearly demonstrated that FoxO1 suppresses $\beta$ cell proliferation and function $(4,9)$. For instance, FoxO1 haploinsufficiency partially reinstates the decreased $\beta$ cell proliferation observed in insulin receptor substrate-2-knockout (Irs2-knockout) mice (10), as well as in mice with $\beta$ cell specific deletion of $P d k 1$, a PI3K-dependent protein kinase that is important in maintenance of $\beta$ cell mass (11). In the hepatocyte, FoxO1 promotes gluconeogenesis by acting in concert with the PPAR $\gamma$ coactivator PGC1 $\alpha$ to stimulate the expression of glucose-6-phosphatase (G6Pase) and phosphoenolpyruvate kinase 1 (Pck1) (6). Thus, FoxO1 controls at least 2 important processes in glucose metabolism: $\beta$ cell proliferation and hepatic glucose production. However, FoxO1 is expressed in many other cell types, where its functions are not known.

Conflict of interest: The authors have declared that no conflict of interest exists. Citation for this article: J. Clin. Invest. 120:357-368 (2010). doi:10.1172/JCI39901.
Recently, it was shown that, in addition to the $\beta$ cell and the hepatocyte, the skeleton may be a regulator of glucose metabolism (12). Osteoblasts, the bone-forming cells, secrete a protein, osteocalcin, that when uncarboxylated acts as a hormone to favor $\beta$ cell proliferation, insulin secretion, insulin sensitivity, and energy expenditure. The function of this bone-derived hormone is negatively regulated by another gene expressed in osteoblasts, Esp. Protein tyrosine phosphatase (OST-PTP), the product of Esp, decreases through an as-yet-unknown mechanism the bioactivity of the osteocalcin protein by favoring its carboxylation.

Because FoxO1 is the main target of insulin action in other tissues, we examined whether it fulfills its metabolic function, in part, through its osteoblastic expression. In this report, we show that FoxO1 helps to control glucose metabolism through 2 regulatory effects in the osteoblast: stimulation of osteocalcin and inhibition of Esp expression. As a result of these complementary functions, FoxO1 through its osteoblastic expression is a negative regulator of energy metabolism.

\section{Results}

Inactivation of Foxo1 in osteoblasts leads to perinatal lethality. To determine which member of the FoxO family was most highly expressed in osteoblasts, we used mouse primary osteoblastic cells. Foxo1 was the most abundant member among the 3 Foxo isoforms of this family of proteins in osteoblasts (Figure 1A). Because of these observations and evidence from several reports identifying the pivotal role of FoxO1 in insulin action and development of type 2 diabetes, angiogenesis, organismal growth, cell differentiation, and tumorigenesis (3), we focused our subsequent studies on FoxO1. 

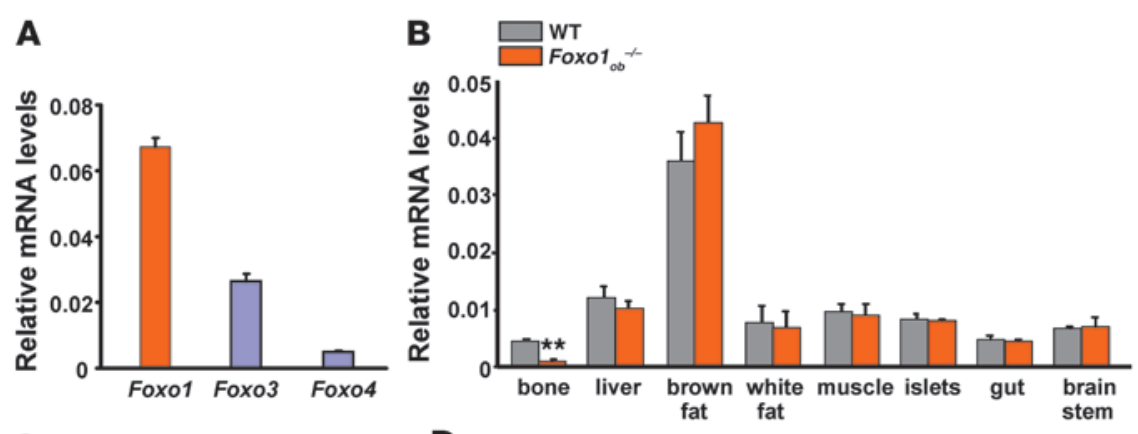

C

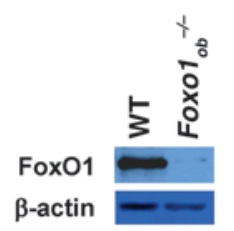

D

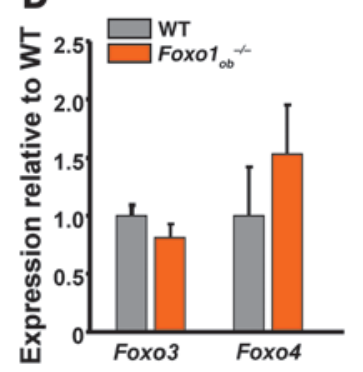

Figure 1

Perinatal lethality in $\mathrm{FoxO}_{\mathrm{ob}^{-/-}}$mice. (A) Real-time PCR analysis of the expression of the 3 Foxo isoforms in primary osteoblasts; $n=3$. (B) Real-time PCR analysis of Foxo1 expression in bone and other tissues of WT and $\mathrm{FoxO}_{o b^{-1-}}$ mice; $n=3$ mice/group. Data are presented as mean \pm SEM; ${ }^{* \star} P<0.01$ by Student's $t$ test. (C) Western blot analysis of FoxO1 protein levels in osteoblasts. (D) Realtime PCR analysis of the expression of $\mathrm{Foxo3}$ and FoxO4 in the femur of WT and FoxO1 ${ }^{-1-}$ mice; $n=3$ /group. In $\mathbf{B}$ and $\mathbf{D}$, mice were 2 months of age.
To conditionally inactivate Foxo1 in osteoblasts $\left(\right.$ Foxo $\left._{o b}{ }^{-/-}\right)$, we bred floxed Foxo1 (Foxo ${ }^{f l / f l}$ ) mice (13) with transgenic mice expressing Cre under the control of the osteoblast-specific collagen type $1 \mathrm{~A} 1$ promoter $\left[\alpha 1(\mathrm{I})\right.$ collagen-Cre] (14-17). Foxo $_{o b}{ }^{+/-}$mice were intercrossed, and animals homozygous for Foxo1 deletion in osteoblasts $\left(\right.$ Foxo $\left._{o b}{ }^{-/-}\right)$were obtained. Foxo1 expression was reduced by nearly $75 \%$ in bone derived from Foxo $1_{o b}{ }^{-/-}$mice (Figure 1B). Foxo 1 expression was unaffected in a variety of different tissues examined, including liver, gut, pancreas, brown and white adipose tissue, skeletal muscle, and brain stem (Figure 1B). Consistent with the decrease in gene expression, FoxO1 protein was barely detected in osteoblasts derived from Foxo $1_{o b} b^{-/-}$mice (Figure 1C). The expression of Foxo3 and Foxo 4 was not affected in the bone of Foxo $1_{o b} b^{-1-}$ mice, thus precluding the possibility that any phenotype may be due to altered expression of the other 2 Foxo isoforms (Figure 1D).

Foxo $1_{o b}{ }^{-/-}$mice were not obtained according to the expected Mendelian ratio (Foxo1 ${ }_{o b}{ }^{+++}: 168$ pups, 55.6\%; Foxo1 ${ }_{o b}^{+/-}: 72$ pups, $23.8 \%$; Foxo $1_{o b}{ }^{-1-}: 62$ pups, $20.5 \%$ ), and in fact, many of them died after birth and before weaning. Indeed, when analyzed at weaning, the survival rate of Foxo $1_{o b}{ }^{-/-}$pups born to Foxo $1_{o b}{ }^{+/-}$ females decreased by $16.8 \%$ (Table 1 ). There was an even greater $50 \%$ reduction in the survival rate of $\mathrm{Foxo}_{0 b^{-/-}}$pups born from Foxo $1_{o b}{ }^{-/-}$mothers. The increased lethality could be due to a number of factors, such as defective skeletogenesis. Analysis of skeletal preparations of newborn WT and Foxo $1_{o b}{ }^{-1-}$ pups indicated that Foxo1 deletion did not result in any gross skeletal abnormalities (data not shown). The lack of any gross skeletal abnormalities in Foxo $1_{o b^{-1-}}$ pups suggested that other factors, such as abnormalities in glucose metabolism, could be playing a role in the reduced survival rate of $\mathrm{FoxO}_{o b}{ }^{-/-}$newborn mice.

Increased $\beta$ cell proliferation and insulin secretion in Foxo $1_{o b}{ }^{-/-}$mice. Measurements of blood glucose levels at birth and before milk ingestion revealed a 1.8-fold reduction in blood glucose levels in Foxo $1_{o b}{ }^{-1-}$ as compared with WT animals (Figure 2A). In fact, in $33 \%$ of the mutant pups, glucose levels were below the levels of assay detection. The observed hypoglycemia could be due to increased insulin production, increased insulin sensitivity, or a combination of both. Remarkably, a 1.6-fold decrease in glucose levels and a 2-fold elevation in insulin levels were detected in adult Foxo $1_{o b}{ }^{-1-}$ mice (Figure 2, B and C). Increased plasma insulin levels after glucose injection were further demonstrated in $\mathrm{Foxo}_{o b}{ }^{-/-}$ mice (Figure 2D). Further, Foxo $1_{o b}{ }^{-/-}$mice were characterized by higher islet numbers, greater islet size, and greater $\beta$ cell mass in the pancreas (Figure $2 \mathrm{E}$ ). $\beta$ Cell proliferation was increased by $75 \%$ in Foxo $1_{o b}^{-/-}$mice (Figure 2F).

Fasting glucose levels were reduced by $36 \%$ in adult Foxo $1_{o b}^{-1-}$ mice (Figure $2 \mathrm{G}$ ). Disposal of a glucose load in response to elevated insulin levels was tested by performing glucose tolerance tests (GTTs) (Figure 2H). Foxo $1_{o b}{ }^{-/-}$mice displayed a marked improvement in glucose tolerance as compared with WT animals. In a separate GTT, we confirmed that the lack of any metabolic phenotype in floxed Foxo1 mice was identical to that of collagen-Cre mice as well as to that of mice with intact alleles (Supplemental Figure 1A; supplemental material available online with this article; doi:10.1172/JCI39901DS1).

It has long been recognized that the incretins, glucose-dependent insulinotropic polypeptide (GIP) and glucagon-like peptide-1 (GLP-1), are hormones released from endocrine cells of the gut mucosa that stimulate insulin secretion from pancreatic $\beta$ cells in a glucose-dependent manner (18-21). Thus, we also examined whether the metabolic phenotype of $\mathrm{Foxol}_{o b}{ }^{-/-}$mice involved changes in this important pathway by performing parallel oral and intraperitoneal glucose tolerance tests (OGTT and IPGTT) (22,

\section{Table 1}

Lower survival at birth of $\mathrm{FoxO}_{o b}{ }^{-/-}$pups born from FoxO1 ${ }_{o b}{ }^{+-}$ and FoxO1 ${ }_{o b}^{-1-}$ mothers

\begin{tabular}{lccc} 
Male & Female & No. of pups & Survival (\%) \\
$\mathrm{fl} / \mathrm{fl}$ & $+/-$ & 178 & 83.0 \\
$+/-$ & $\mathrm{fl} / \mathrm{fl}$ & 93 & 86.0 \\
$\mathrm{fl} / \mathrm{fl}$ & $-/-$ & 26 & 50.0 \\
$-/-$ & $\mathrm{fl} / \mathrm{fl}$ & 89 & 78.7 \\
\hline
\end{tabular}


A

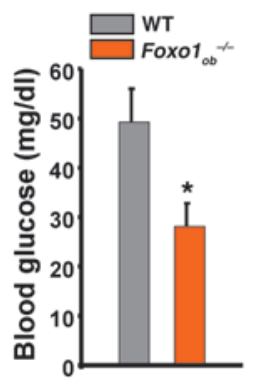

B

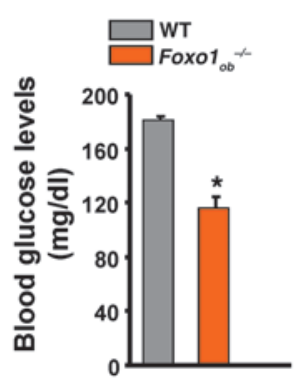

WT

E
C

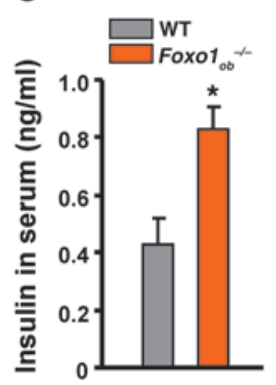

Foxo1 ${ }_{o b}^{-1}$
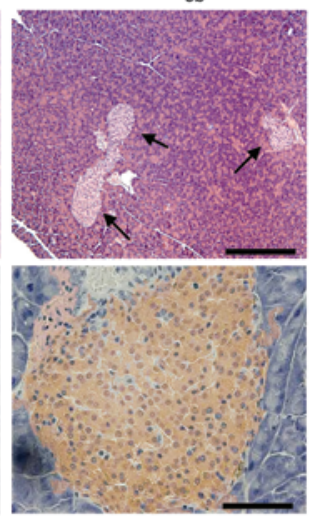

$\beta$-cell mass (mg)

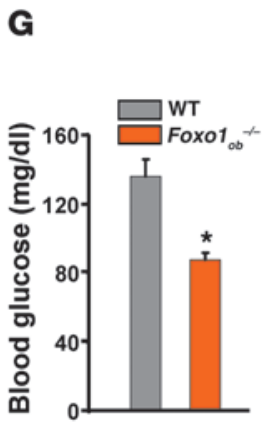
$1.33 \pm 0.12^{*}$
$1.11 \pm 0.20$ *
$0.99 \pm 0.19^{*}$
$0.96 \pm 0.09$
$0.53 \pm 0.08$
$0.41 \pm 0.07$

H

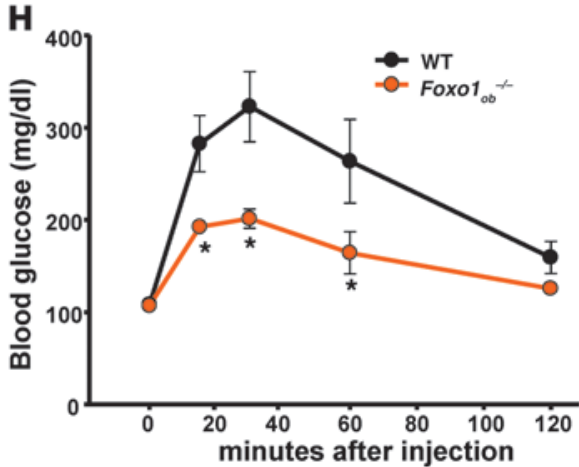

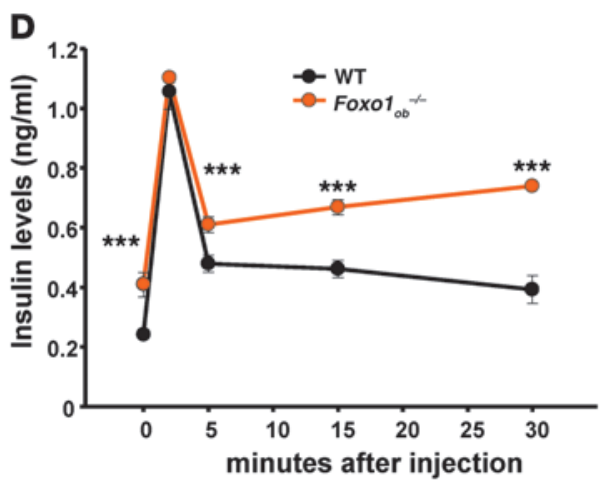

F
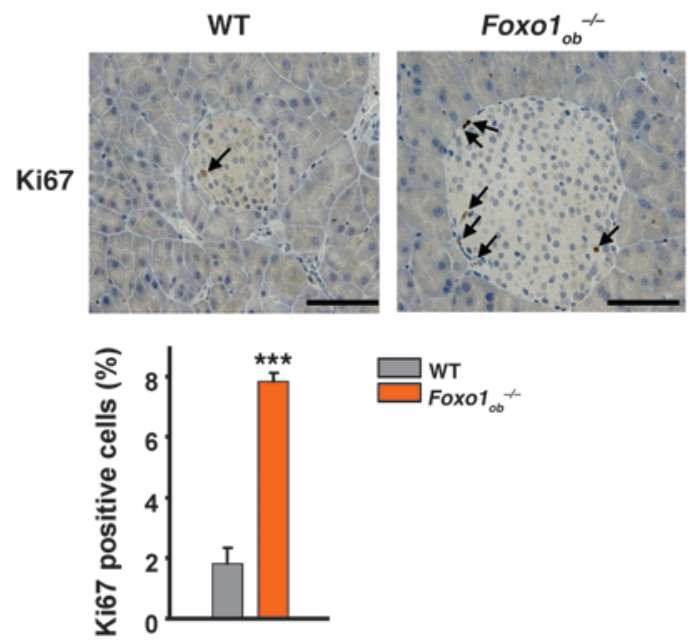

I

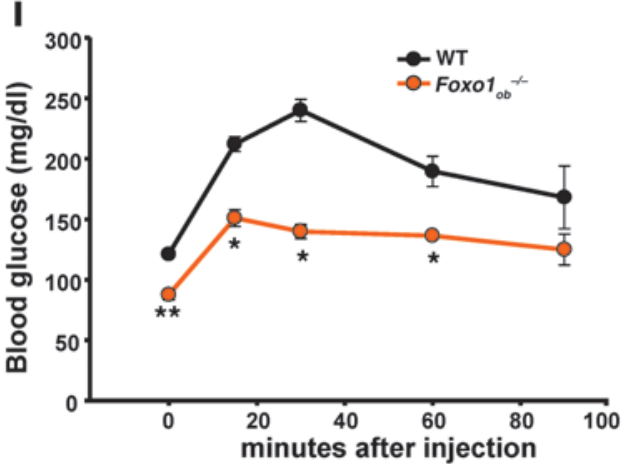

Figure 2

Increased $\beta$ cell proliferation and insulin secretion in Foxo1 ${ }_{o b}{ }^{-1-}$ mice. (A) Blood glucose levels in WT and Foxo ${ }_{o b}{ }^{-/-}$newborn before milk ingestion; $n=5$ pups. (B) Blood glucose and (C) serum insulin levels in WT and Foxo1 ${ }_{o b}{ }^{-/-}$mice at random feeding; $n=5$. (D) Plasma insulin levels after glucose injection in WT and Foxo1 ${ }_{o b}{ }^{-1-}$ mice; $n=4 /$ group. (E) H\&E and insulin staining and (F) Ki67 immunostaining showing larger islets and increased $\beta$ cell proliferation in the pancreas of $F_{0 x O{ }_{o b}-1-}$ mice; $n=5$ mice/group. Scale bars represent $100 \mu \mathrm{m}$, except in the H\&E panels, where they represent $800 \mu \mathrm{m}$. (G) Fasting blood glucose levels in WT and Foxo ${ }_{o b}{ }^{-1-}$ adult mice; $n=5$ mice/group. (H) GTT in WT and Foxo1 ${ }_{o b}^{-1-}$ mice; $n=5$ mice/ group. (I) PTTs in WT and Foxo1 ${ }_{o b}^{-1-}$ mice; $n=5$ mice/group. In all panels, data are presented as mean \pm SEM. ${ }^{\star} P<0.05,{ }^{* \star} P<0.01,{ }^{* \star *} P<0.001$ by Student's $t$ test. In B-I, all mice were 2 months of age.

23). As expected, WT animals showed improved glucose tolerance when glucose was administered orally due to the contribution of incretins to glucose metabolism (Supplemental Figure 1, B and D). We also found that Foxo1 ${ }_{o b}{ }^{-1-}$ mice had improved glucose tolerance in the oral as compared with the i.p. challenge test (Supplemental Figure 1, C and D). Similar to the IPGTT, Foxo $1_{o b}{ }^{-1-}$ mice showed improved glucose tolerance as compared with WT control animals following oral glucose administration (Supplemental Figure
1, E and F). These results do suggest that the incretin pathway is preserved in the Foxo $1_{o b}{ }^{-1-}$ mice and that it may be an important mediator of the effects of osteoblast-expressed FoxO1 on glucose homeostasis. However, further gene inactivation experiments will be required to obtain a definitive answer.

Consistent with their hyperinsulinemia, gluconeogenesis was suppressed in Foxo $1_{o b}{ }^{-/-}$mice (Figure 2I). Next, we examined a potential contribution of counterregulatory hormones to the metabolic phe- 
A

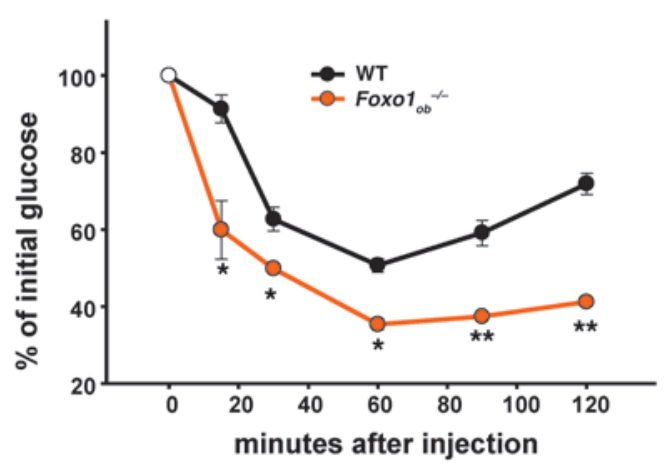

C

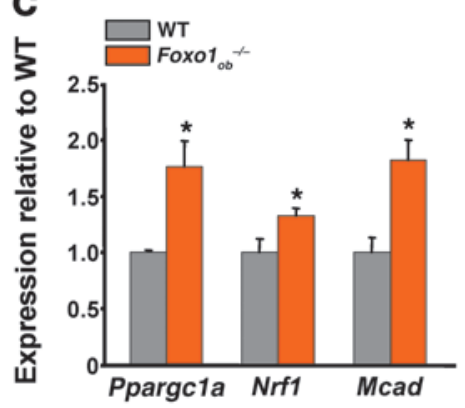

F

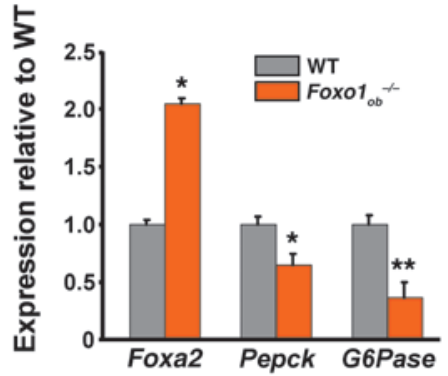

B $\square$ wT

Foxo1 ${ }_{0 b}+$

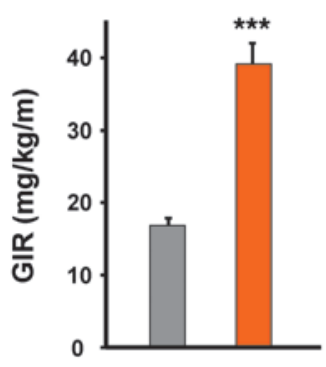

$\square$ WT Foxo1 $_{a b}{ }^{-}$

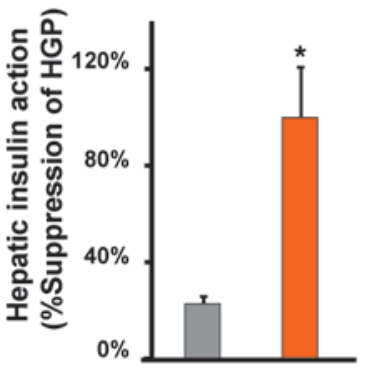

D

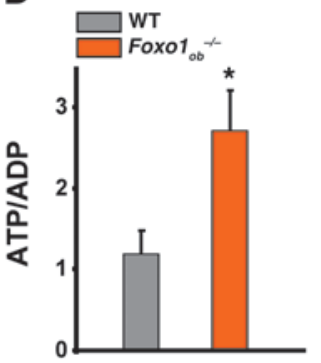

G

E
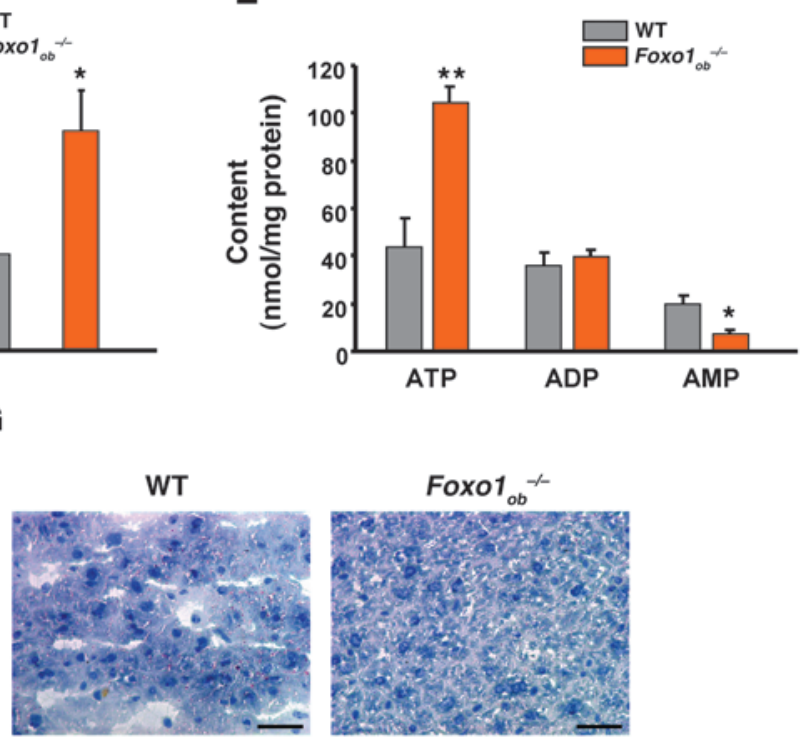

Figure 3

Increased insulin sensitivity in Foxo1 $a b^{-/-}$mice. (A) ITTs in WT and Foxo1 ${ }_{o b}^{-1-}$ mice; $n=5$ mice/group. (Identical data are shown in Figure 5E.) (B) Glucose infusion rate (GIR) and suppression of hepatic glucose production (HGP) (\% of clamp HGP relative to basal HGP) in WT $(n=3)$ and Foxo1 $_{\mathrm{Ob}^{-/-}}(n=5)$ mice by hyperinsulinemic-euglycemic clamps. (C) Real-time PCR analysis of insulin target gene expression in skeletal muscle of WT and Foxo1 $o^{-1-}$ mice. Values are expressed as fold increase relative to WT; $n=4$ mice/group. (D and E) HPLC analysis of adenine nucleotide levels in the vastus lateralis muscle; $n=4$ mice/group. (F) Real-time PCR analysis of insulin target genes in the liver of WT and Foxo $1_{o b}{ }^{-1-}$ mice; $n=4$ mice/group. (G) Oil red O staining in liver sections of WT and Foxo ${ }_{o b}{ }^{-1-}$ mice; $n=4$ mice/group. Scale bars: $100 \mu \mathrm{m}$. In all panels, data are presented as mean \pm SEM. ${ }^{*} P<0.05,{ }^{* \star} P<0.01,{ }^{* \star \star} P<0.001$ by Student's $t$ test. All mice were $2-3$ months of age.

notype of Foxo $1_{o b}{ }^{-1-}$ mice. The percentage of glucagon-expressing $\alpha$ cells as well as blood levels of glucagon and growth hormone which have anti-insulin activity, as they suppress the ability of insulin to stimulate glucose uptake in peripheral tissues (24) - were not affected in $\mathrm{Foxo1}_{o b^{-/-}}$mice (Supplemental Figure 2, A-C). Moreover, because FoxO1 regulates food intake and peripheral metabolism by interacting with leptin signaling in the hypothalamus $(25,26)$, we verified that Foxo1 deletion did not occur in the hypothalamus. As shown in Supplemental Figure 2, D and E, $\alpha 1$ (I) collagen-Cre-mediated deletion of Foxo1 occurred in bone but not in the hypothalamus. Collectively, the data indicate that FoxO1, through its expression in osteoblasts, inhibits insulin secretion.

Increased insulin sensitivity in Foxo $1_{o b}{ }^{-1-}$ mice. To determine whether an increase in insulin sensitivity contributes to the low glucose levels and improved glucose disposal in Foxo $1_{o b} b^{-1-}$ mice we performed insulin tolerance tests (ITTs). This test showed that Foxo $1_{o b}{ }^{-/-}$mice had increased insulin sensitivity as compared with WT animals (Figure $3 \mathrm{~A}$ and identical data shown below). To further examine insulin sensitivity in individual organs, we performed a 2-hour hyperinsulinemic-euglycemic clamp in conscious mice. We detected increased insulin-stimulated glucose disposal, as reflected by a higher glucose infusion rate in Foxo1 ${ }_{o b}{ }^{-1-}$ mice as compared with WT controls (Figure $3 \mathrm{~B})$. Moreover, insulin's ability to suppress hepatic glucose production increased in $\mathrm{FoxO}_{o b}{ }^{-/-}$mice relative to WT littermates (Figure $3 \mathrm{~B})$. Basal hepatic glucose production rates were not altered in Foxo $1_{o b}{ }^{-/-}$mice $(17.56 \pm 1.35 \mathrm{mg} / \mathrm{kg} / \mathrm{min}$ in WT versus $16.04 \pm 2.08$ $\mathrm{mg} / \mathrm{kg} / \mathrm{min}$ in Foxo $1_{o b}{ }^{-/-}$mice). Consistent with higher insulin levels and greater insulin sensitivity, the expression of the insulin target gene Ppargcla was increased in the muscle of Foxo $1_{o b}{ }^{-1-}$ mice as compared with WT animals (Figure 3C). The expression of 2 Ppargc1a 
A

B

WT
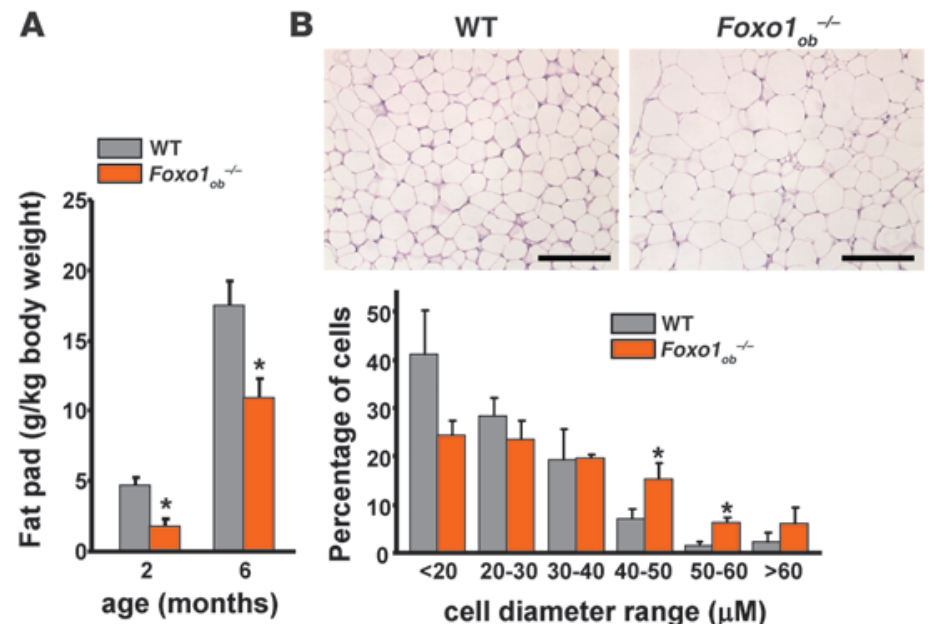

C
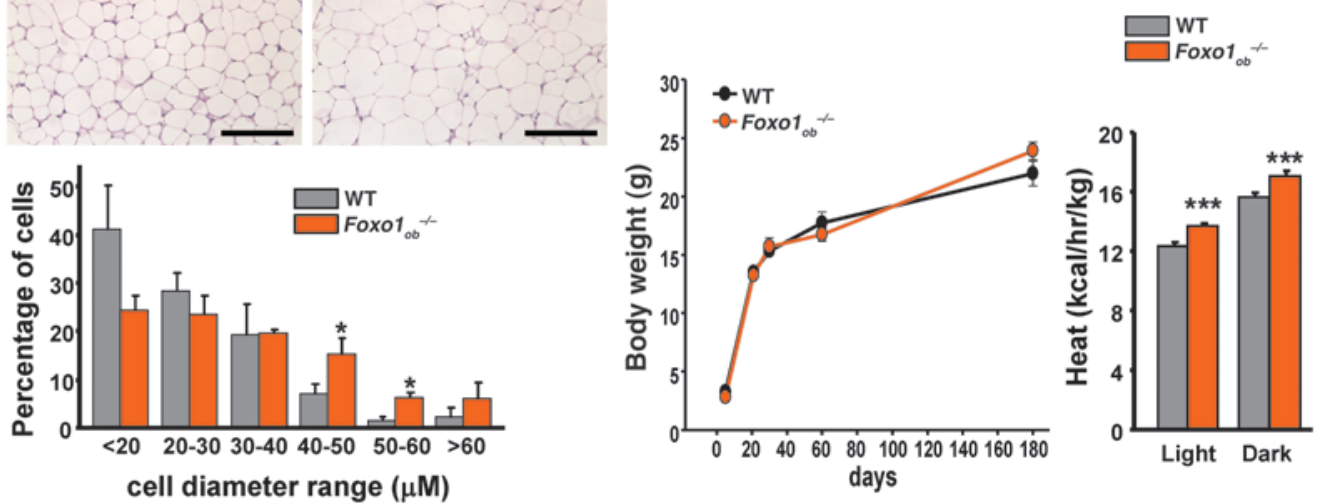

E

F

F

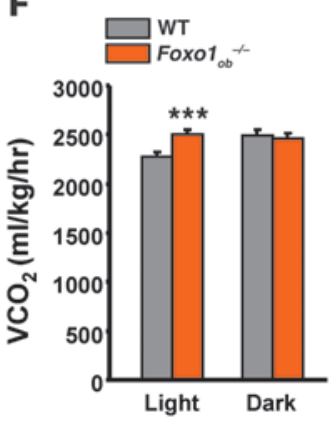

G

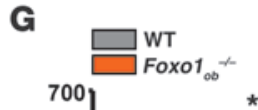

H
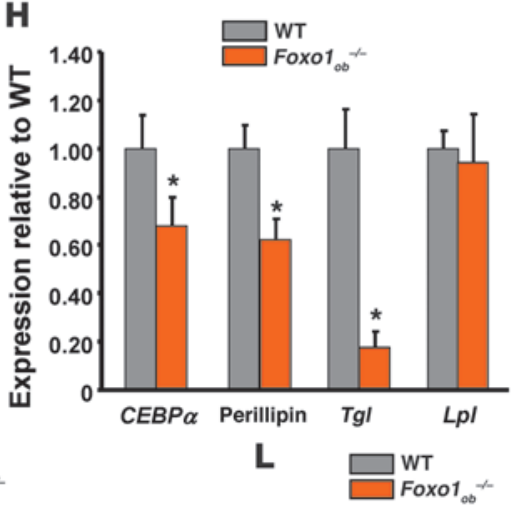

I

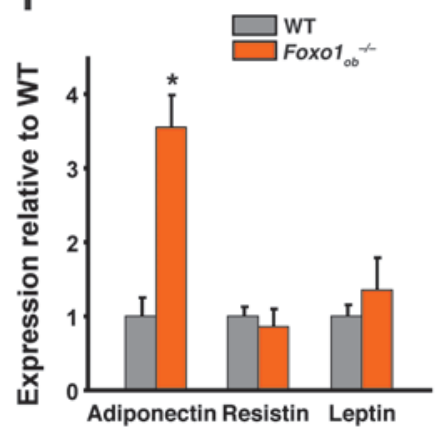

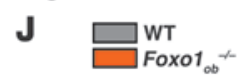

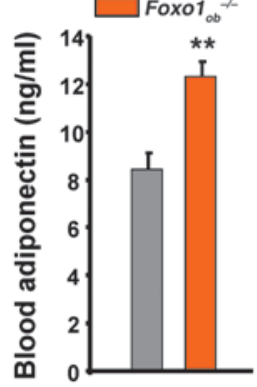

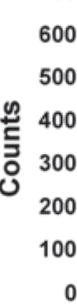
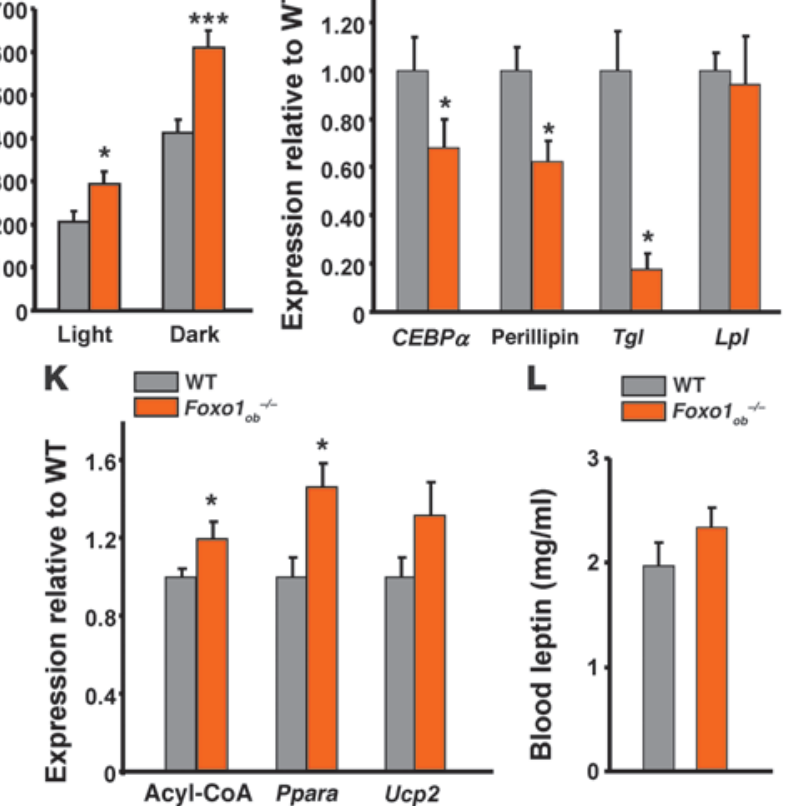

Figure 4

Fat metabolism in Foxo1 ${ }_{o b}^{-1-}$ mice. (A) Gonadal fat pad weight in WT and Foxo1 $o b^{-/-}$mice; $n=7$ mice/group. (B) Histomorphometric analysis of white fat sections of WT and Foxo ${ }_{o b}{ }^{-1-}$ mice; $n=5$ mice/group. Scale bars: $400 \mu \mathrm{m}$. (C) Body weight curve analysis of WT and Foxo ${ }_{o b}{ }^{-1-}$ mice from day 5 until 6 months of age; $n=7$ mice/group. (D-G) Heat production, oxygen consumption, $\mathrm{CO}_{2}$ expenditure, and total activity (counts) by indirect calorimetric analysis in adult WT and Foxo1 $\mathrm{ob}^{-1-}$ mice; $n=6$ mice/group. (H and I) Real-time PCR analysis of insulin target genes in white fat of WT and Foxo ${ }_{o b} b^{--}$mice; $n=4$ mice/group. (J) Serum adiponectin levels in WT and Foxo ${ }_{o b}{ }^{-1-}$ mice; $n=5$ mice/group. (K) Real-time PCR analysis of adiponectin target genes in skeletal muscle of WT and Foxo1 ob ${ }^{-1-}$ mice; $n=5$ mice/group. (L) Serum leptin levels in WT and Foxo1 ${ }_{o b}{ }^{-1-}$ mice; $n=4$ mice/group. In all panels, bars indicate mean \pm SEM. ${ }^{*} P<0.05,{ }^{* *} P<0.01,{ }^{* * *} P<0.001$ by Student's $t$ test. In all panels except C, mice were $2-3$ months of age.

target genes, Nrf1 and Mcad, was also increased. Because Ppargc1a expression is associated with mitochondrial activity, we examined the possibility that $\mathrm{Foxo}_{o b}{ }^{-/-}$mice have altered mitochondrial activity. Measurements of ATP and AMP levels in the same muscles demonstrated a higher ATP/ADP ratio in Foxo $1_{o b}{ }^{-/-}$mice as compared with WT controls (Figure 3D). This was due to an increase in the ATP production (Figure $3 \mathrm{E}$ ) and together with the decreased levels of AMP indicated higher mitochondrial activity in $\mathrm{Foxo}_{o b}{ }^{-1-}$ mice. To further confirm these observations, we measured in muscle the expression of biomarkers in the oxidative phosphorylation metabolic pathway, which uses energy released by the oxidation of nutrients to produce ATP (27). Expression of uncoupling protein 3 (Ucp3), muscle carnitine palmitoyl transferase I (Cpt1b), and pyruvate dehydrogenase kinase 4 (Pdk4) was increased in the muscle of Foxo $1_{o b}{ }^{-1-}$ mice as compared with WT controls (Supplemental Figure 3A). Similarly, levels of mitochondrial respiratory chain proteins were also upregulated in the muscle of Foxo $1_{o b}{ }^{-1-}$ mice as compared with WT controls (Supplemental Figure 3B). Specifically, we found increased levels of mitochondrial DNA-encoded (mtDNA-encoded) subunits: subunit 6 of NADH dehydrogenase (ND6, complex I) and subunit I of cyto- 
A
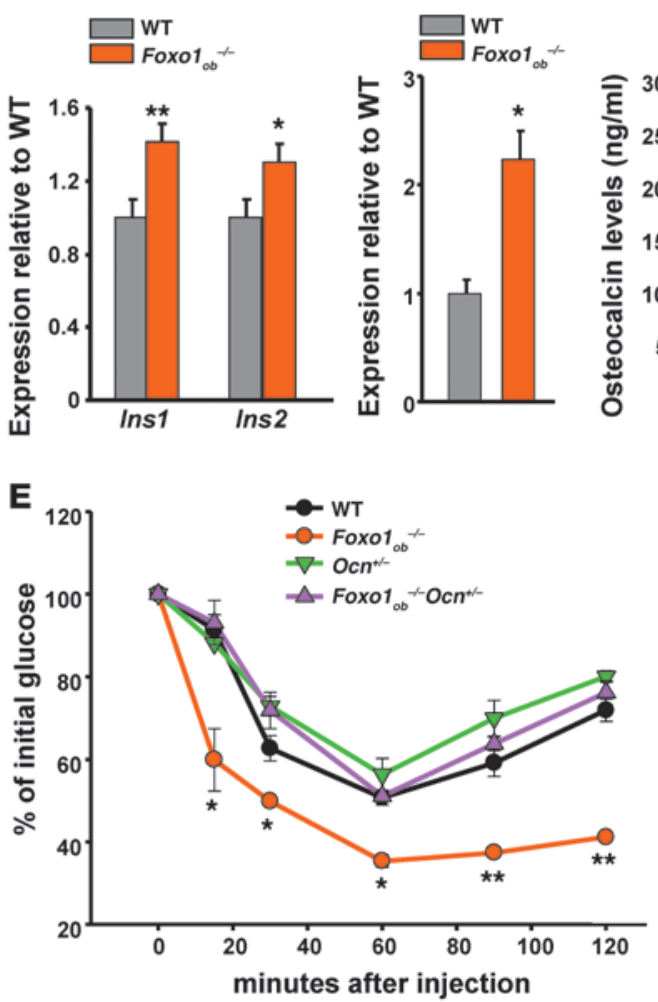

B

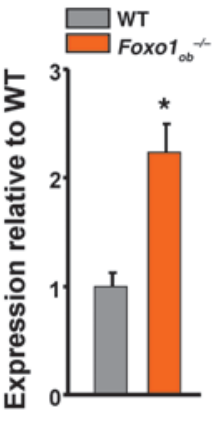

C

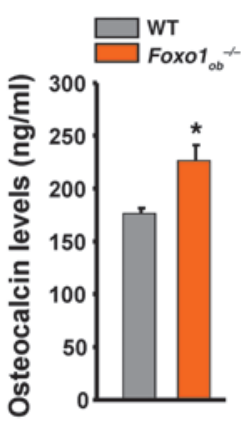

D

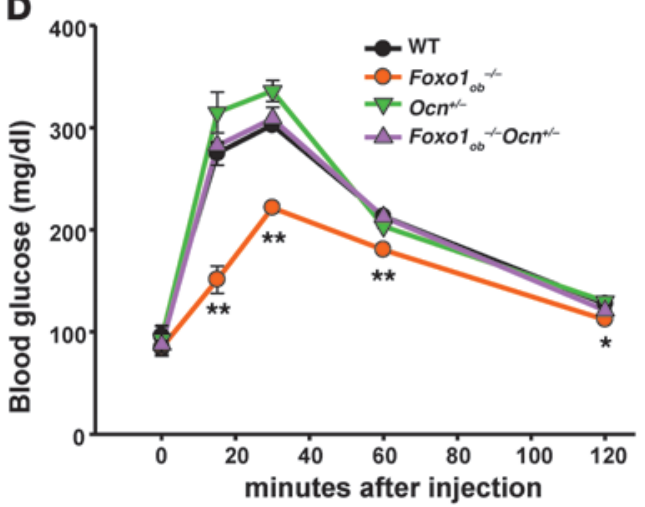

$\mathbf{F}$

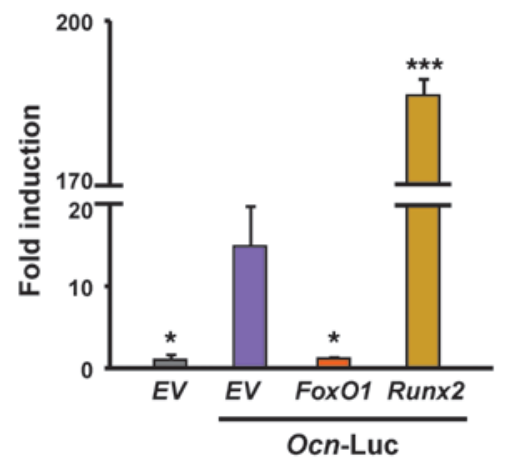

$\mathbf{H}$
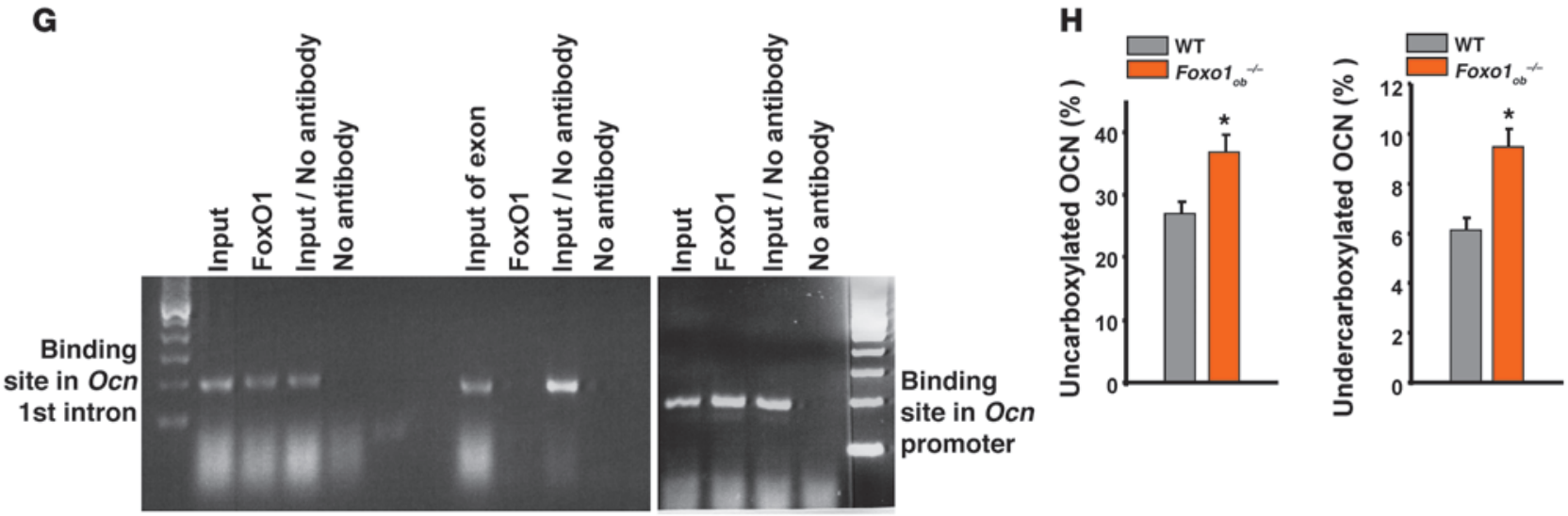

Figure 5

Foxo1 in osteoblasts regulates glucose homeostasis through regulating osteocalcin. (A) Expression analysis of the 2 insulin genes (Ins1 and Ins2) in WT islets cultured with WT or Foxo1 ${ }_{o b}^{-1-}$ primary osteoblasts. (B) Real-time PCR analysis of osteocalcin expression in WT and Foxo1 ob ${ }^{-1-}$

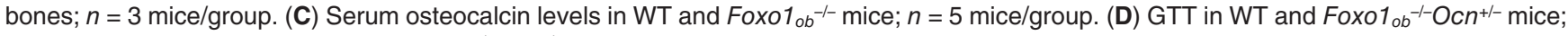
$n=5$ mice/group. (E) ITT in WT and Foxo1 $\mathrm{ob}^{-1-} \mathrm{Ocn}^{+/-}$mice; $n=5 \mathrm{mice} /$ group. (F) Cotransfection analysis of FoxO1 interaction with the Ocn promoter in Cos-7 cells. Results are presented as fold induction over EV $(E V=1)$. (G) ChIP analysis of FoxO1 binding to the Ocn promoter and the first intron

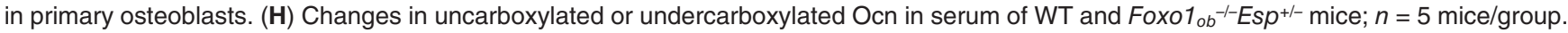
Values are presented as percent of total osteocalcin present in the serum. In all panels, data are presented as mean \pm SEM. ${ }^{\star} P<0.05$, ${ }^{* *} P<0.01,{ }^{* *} P<0.001$ by Student's $t$ test for $\mathbf{A}-\mathbf{C}, \mathbf{F}$, and $\mathbf{H}$ and ANOVA for $\mathbf{D}$ and $\mathbf{E}$. Mice were $2-3$ months of age.

chrome c oxidase (COXI, complex IV) in the muscle of Foxo $1_{o b}{ }^{-/-}$mice as compared with WT controls. In contrast, levels of nuclear-encoded proteins Core 2 and $\mathrm{CV} \alpha$ were similar in $\mathrm{Foxo}_{o b^{-/}}$and WT animals.

The expression of several insulin target genes was examined in other tissues. In the liver, expression of Foxa2, which regulates lipogenesis and ketogenesis during fasting, was increased in Foxo1 ${ }_{o b}^{-/-}$mice (Figure 3F), whereas expression of G6Pase and
Pck1 was decreased in Foxo $1_{o b}{ }^{-1-}$ as compared with WT mice. This feature was consistent with suppression of gluconeogenesis by increased insulin levels in Foxo $1_{o b}{ }^{-1-}$ mice. Liver fat content was decreased in Foxo $1_{o b}{ }^{-1-}$ as compared with WT mice, consistent with the improved insulin sensitivity observed in $\mathrm{Foxo1}_{o b}{ }^{-/-}$mice (Figure $3 \mathrm{G})$. These results indicate that FoxO1, through its expression in osteoblasts, inhibits insulin sensitivity in the liver and muscle. 
A

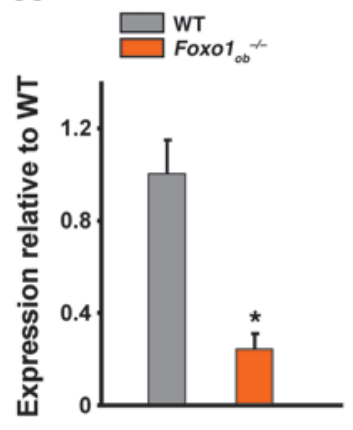

c

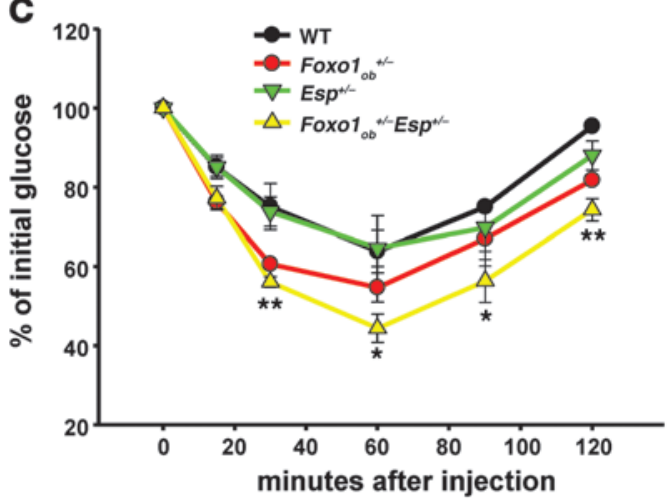

E

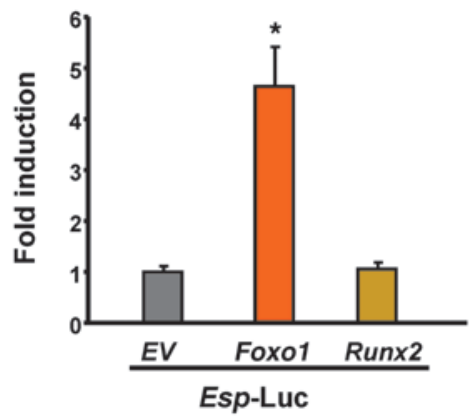

F
B

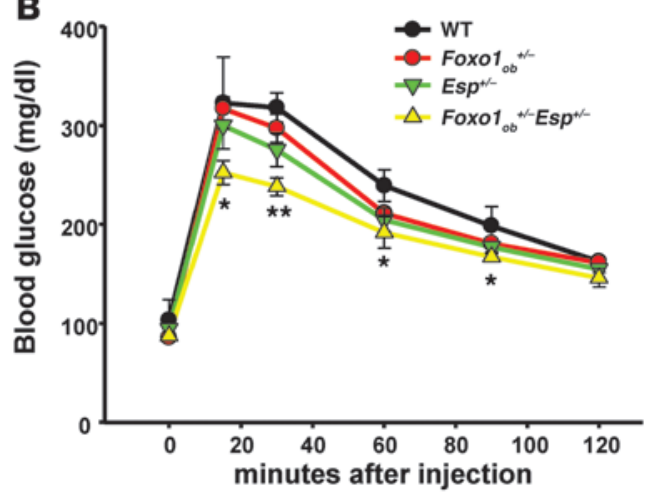

D

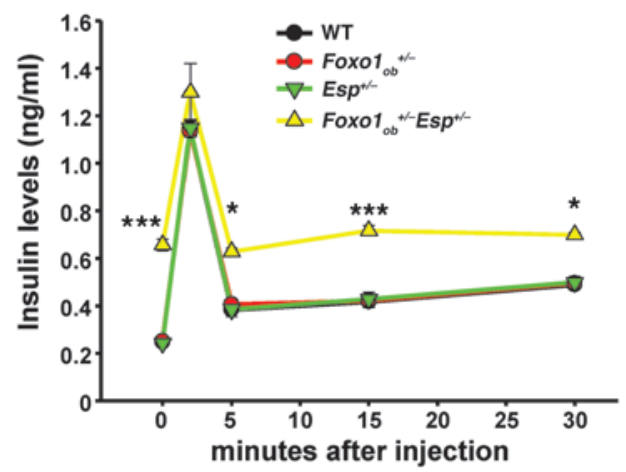

FoxO1 binding site in Esp

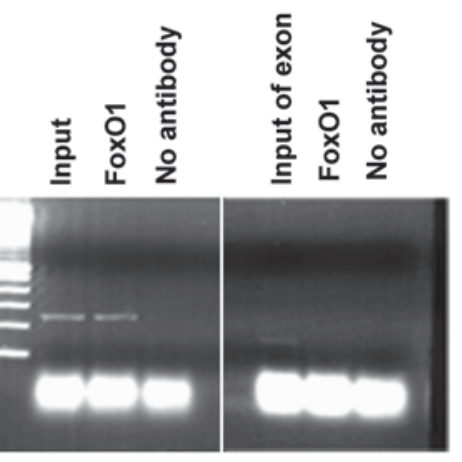

Figure 6

Esp mediates the effect of Foxo1 on osteocalcin carboxylation and glucose homeostasis. (A) Real-time PCR analysis of Esp expression in femurs

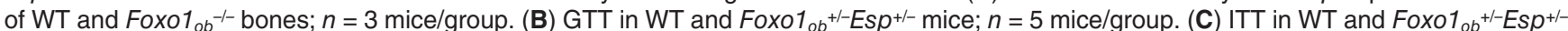

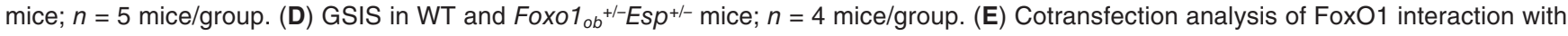
the Esp promoter in Cos-7 cells. Results are presented as fold induction over EV (EV = 1). (F) ChIP analysis of FoxO1 binding to the Esp promoter in primary osteoblasts. In all panels, data are presented as mean \pm SEM. Lanes were run on the same gel but were not contiguous. ${ }^{\star} P<0.05,{ }^{* *} P<0.01,{ }^{* * *} P<0.001$ by Student's $t$ test for $\mathbf{A}$ and $\mathbf{E}$ and ANOVA for $\mathbf{B}-\mathbf{D}$. Mice were 2 months of age.

Despite their hyperinsulinemia and improved insulin sensitivity, Foxo $1_{o b}{ }^{-1-}$ mice showed a decrease in the weight of gonadal fat as compared with WT animals (Figure 4A). Adipocyte numbers were also decreased, by $38 \%$, whereas adipocyte size was increased in adult Foxo $_{o b}{ }^{-1-}$ mice (Figure 4B). Only perigonadal fat was affected, as there were no differences in total fat content between Foxo $_{o b^{-/-}}$and WT mice (Supplemental Figure 4A). Lean body mass (Supplemental Figure 4B) and body weight (Figure 4C) were also not affected in Foxo $1_{o b}{ }^{-1-}$ mice. Explaining, at least in part, the low gonadal fat weight of the Foxo $1_{o b}{ }^{-/-}$mice, energy expenditure increased by $10 \%$, as compared with that of WT animals (Figure 4D). Foxo1 deletion in osteoblasts also increased oxygen and $\mathrm{CO}_{2}$ consumption by $10 \%$ (Figure $4, \mathrm{E}$ and $\mathrm{F}$ ). Consistent with the increase in energy expenditure, activity levels were increased by $40 \%$ in Foxo $_{o b}{ }^{-/-}$mice (Figure $4 \mathrm{G}$ ). In contrast, energy intake was not affected in $\mathrm{Foxo}_{o b^{-/-}}$mice (Supplemental Figure 4C). The increase in adipocyte size, in spite of the decrease in perigonadal fat weight and the increase in mitochondrial activity in Foxo $1_{o b}{ }^{-1-}$ compared with WT mice, suggests that adipocyte differentiation may be compromised in the Foxo $1_{o b}{ }^{-/-}$animals.

Consistent with the decrease in gonadal fat weight, the expression of the adipogenic gene Cebpa and 2 lipolytic genes, perilipin and triglyceride lipase $(T g l)$, whose expression is inhibited by insulin, was decreased in Foxo $1_{o b}{ }^{-/}$as compared with WT mice (Figure 

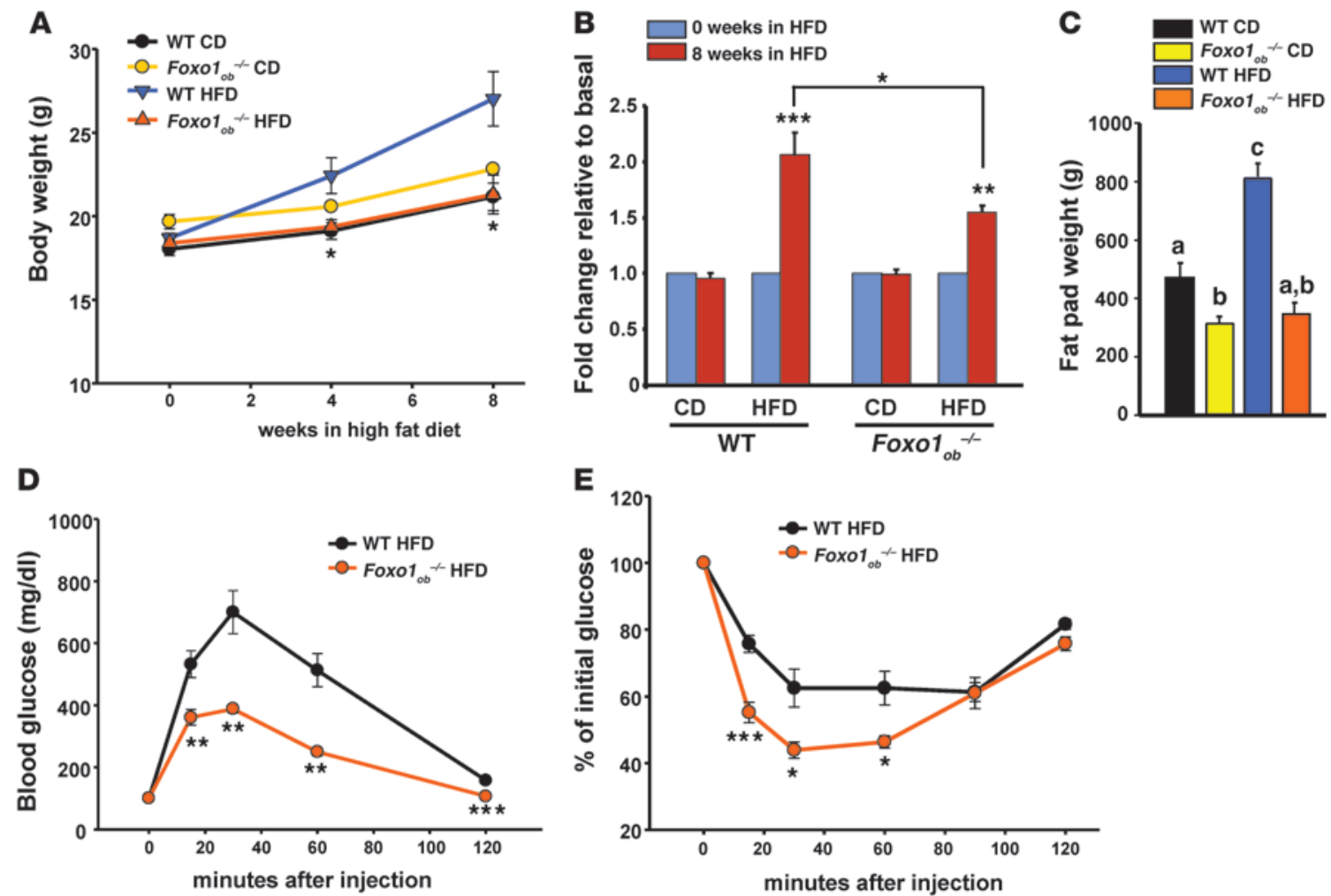

Figure 7

Foxo1 deletion in osteoblasts protects from HFD-induced obesity. (A and B) Body weight curve (A) and MRI analysis of fat content (B) of WT and Foxo1 ${ }_{o b}^{-1-}$ mice on normal or high-fat diet; $n=5$ mice/group. Basal is considered 1 and is the fat content of each experimental group at 0 weeks, i.e., before the onset of HFD. (C) Perigonadal fat pad weight in WT and Foxo1 ${ }_{o b}^{-1-}$ mice on normal or high-fat diet; $n=5$ mice/group. (D and E) ITT (D) and GTT (E) analysis in WT and Foxo ${ }_{o b}{ }^{-1-}$ mice on normal or high-fat diet; $n=5$ mice/group. CD, normal control diet. In all panels, data are presented as mean \pm SEM. ${ }^{\star} P<0.05,{ }^{* \star} P<0.01,{ }^{* \star \star} P<0.001$ by Student's $t$ test. In $\mathbf{C}$, letters above the bars denote significant differences, where $b$ is different from $a ; c$ is different from $a$ and $b$; and $a, b$ is different from $c$. In $\mathbf{A}-\mathbf{C}$, mice were 1 month old when placed on HFD. In $\mathbf{D}$ and E, mice were 3 months of age.

$4 \mathrm{H})$. Expression of lipoprotein lipase $(L p l)$ was unaffected. These molecular changes indicated that whereas both adipogenesis and lipolysis are decreased with Foxo1 deletion from osteoblasts, lipogenesis and fatty acid uptake are probably not affected.

Adipokines mediating increased insulin sensitivity. To uncover the mechanism leading to an increase in insulin sensitivity in Foxo $1_{o b}{ }^{-1-}$ mice, we studied various adipokines. Expression and serum levels of the insulin-sensitizing hormone adiponectin (28) were increased by Foxo1 deletion in osteoblasts (Figure 4, I and J). Accordingly, expression of the adiponectin targets acyl-CoA oxidase, Ppara, and Ucp2 was increased in the muscle of Foxo $1_{o b}{ }^{-1-}$ mice (Figure 4K). Expression of resistin, an adipokine mediating insulin resistance (29), was not affected by the mutation (Figure 4I). Expression as well as serum levels of the insulin-sensitizing hormone leptin (30) were not affected by Foxo1 deletion in osteoblasts (Figure 4, I and L).

The osteoblast-specific, secreted protein osteocalcin mediates the metabolic actions of FoxO1. To further confirm that Foxo1 regulates glucose homeostasis through its actions in osteoblasts, we performed coculture experiments with osteoblasts (adherent cells) and pancreatic islets (nonadherent cells). Consistent with the hyperinsulinemia characterizing Foxo $1_{o b}{ }^{-/-}$mice, cocultures of Foxo $1_{o b}^{-/-}$ osteoblasts with WT pancreatic islets increased insulin expression by $30 \%$ as compared with the effect of WT osteoblasts cocultured with WT pancreatic islets (Figure 5A).
In search of osteoblast-secreted factors regulating glucose homeostasis, we focused on osteocalcin for 3 reasons. First, expression of osteocalcin in Foxo1 ${ }_{o b}^{-1-}$ as compared with WT mice was increased by $50 \%$ (Figure $5 \mathrm{~B}$ ). In agreement with the expression data, serum osteocalcin levels were 30\% higher in $\mathrm{Foxo}_{o b}{ }^{-1-}$ as compared with WT mice (Figure 5C). Second, osteocalcin has been shown to favor $\beta$ cell proliferation and insulin secretion and sensitivity in pancreatic islets and in mice $(12,31,32)$. Finally, Foxo $1_{o b}{ }^{-/-}$mice have a phenotype that mirrors the metabolic phenotype of mice lacking osteocalcin $\left(\mathrm{Ocn}^{-/-}\right.$ mice), thus suggesting a gain of osteocalcin activity in Foxo $1_{o b}^{-/-}$mice. If our hypothesis is correct, then we would expect that the metabolic phenotype of $\mathrm{Foxo}_{o b} \mathrm{ob}^{-/-}$mice would be rescued by reducing osteocalcin expression. We tested this hypothesis by generating Foxo $_{o b}{ }^{-/-}$mice lacking 1 allele of osteocalcin $\left(\mathrm{Foxo1}_{o b^{-/-}} \mathrm{OCn}^{+/-}\right)$. Indeed, removal of a single osteocalcin allele from $\mathrm{Fox}_{0} 1_{o b}{ }^{-/-}$mice resulted in a complete reversal of the metabolic abnormalities of the Foxo1 ${ }_{o b}{ }^{-/-}$animals (Figure 5, D and E). GTT and ITT tests showed normalization of insulin sensitivity and glucose tolerance. These results provide strong genetic evidence that FoxO1 and osteocalcin lie in the same regulatory pathway and suggest that the metabolic abnormalities in $\mathrm{Foxo1}_{o b}{ }^{-1-}$ mice are mediated by upregulation of osteocalcin activity.

Increased osteocalcin production and decreased carboxylation in Foxo $1_{o b}{ }^{-1-}$ mice. To identify the mechanism of the molecular interactions between FoxO1 and osteocalcin, we examined whether FoxO1 
regulates osteocalcin activity. In DNA cotransfection experiments performed in Cos-7 cells, a Foxo1 expression vector decreased the activity of a reporter construct containing a $2.9-\mathrm{kb}$ fragment of the osteocalcin promoter fused to the luciferase gene (Figure 5F). Runx2, an osteoblastic-specific transcription factor known to increase osteocalcin expression (33), stimulated the activity of the osteocalcin reporter construct. Moreover, and as indicated by ChIP assays, FoxO1 binds to FoxO1-binding sites present in the promoter as well as the first intron of the osteocalcin gene (Figure $5 \mathrm{G})$. The promoter region examined contains 2 FoxO1-binding sites. They are located at positions $-1,270 \mathrm{bp}$ (TGTTTTG) and $1,074 \mathrm{bp}$ (TGTTTT). A FoxO1-binding site (TGTTTGC) is present at +250 bp of the first intron.

Next, we examined the levels of uncarboxylated osteocalcin, which has been implicated as having a beneficial role in the control of glucose homeostasis (12), in Foxo $1_{o b}{ }^{-1-}$ mice. After an incubation period of 60 minutes, $37 \%$ of osteocalcin present in the serum of Foxo $1_{o b}{ }^{-1-}$ mice was uncarboxylated, whereas only $27 \%$ of uncarboxylated osteocalcin was present in the serum of WT mice. Undercarboxylated osteocalcin was present at $9.5 \%$ and $6.1 \%$ in Foxo $_{o b}{ }^{-/-}$and WT mice, respectively (Figure $5 \mathrm{H}$ ). These experiments suggest that FoxO1 in osteoblasts controls glucose homeostasis by regulating both the expression and carboxylation of osteocalcin.

OST-PTP mediates the effects of FoxO1 on osteocalcin carboxylation and glucose homeostasis. OST-PTP has been shown to influence osteocalcin function by promoting $\gamma$-carboxylation (12). Mice deficient in Esp, the gene encoding OST-PTP $\left(E s p^{-/-}\right.$mice $)$have a metabolic phenotype resembling that of Foxo $1_{o b}{ }^{-/-}$mice. Moreover, expression of Esp was reduced by $75 \%$ in Foxo $1_{o b}{ }^{-/-}$mice as compared with WT mice (Figure 6A). Collectively, these observations suggested that downregulation of Esp activity in Foxo $1_{o b}{ }^{-/-}$mice could account for the decrease in osteocalcin carboxylation and the metabolic phenotype of the FoxO1 mutant mice. In support of this notion, insulin sensitivity and glucose tolerance were improved in mice lacking a single allele of Foxo1 and Esp (Foxo $\left.1_{o b}{ }^{+/-} \mathrm{Esp}^{+-}\right)$(Figure 6, B-D). Metabolic changes were not observed in $\mathrm{Foxo}_{o b}{ }^{+/-}$or $\mathrm{Esp}^{+/-}$mice.

We explored further the mechanism of the stimulatory effect of FoxO1 on Esp expression using Cos-7 cells. Transfection of a FoxO1 expression vector stimulated the activity of Esp as measured using an Esp reporter construct that carries 722 bp of the promoter region and 1,095 bp of the first intron and exon of the gene (region -722 to $+1,095$ ) (Figure 6E). This region of Esp was selected because it contains 2 putative FoxO1-binding sites present at positions $+137 \mathrm{bp}($ TGTTTTT) and $+947 \mathrm{bp}$ (TGTTTTT) of the first intron of the gene. This effect was specific for FoxO1, since transfection of the osteoblast-specific transcription factor Runx2 had no effect on Esp activity. In addition, ChiP assays revealed that FoxO1 binds to the $-1,098$ site of the Esp first intron (Figure 6F). Thus, the stimulatory effect of FoxO1 on Esp expression results, at least in part, from direct binding of FoxO1 to Esp.

FoxO $1_{o b}{ }^{-1-}$ mice are protected from high-fat diet-induced obesity. Last, we decided to test the therapeutic relevance of these findings. Hyperinsulinemia and increased insulin sensitivity in $\mathrm{FoxO}_{\mathrm{ob}}{ }^{-/-}$mice could be effective in protecting these animals from obesity. To examine this hypothesis, we fed Foxo $1_{o b}{ }^{-1-}$ and WT mice a high-fat diet (HFD) for 8 weeks. Foxo $1_{o b}{ }^{-1-}$ mice gained significantly less body weight and total fat content than WT animals (Figure 7, A and B). Perigonadal fat pad weight was not affected by HFD in Foxo $1_{o b}{ }^{-1-}$ mice (Figure 7C). Accordingly, the development of glucose intolerance and insulin resistance, a feature of the fat-fed WT mice, was mark- edly decreased in $\mathrm{Foxo1}_{o b}{ }^{-/-}$mice (Figure 7, D and E). These experiments establish that FoxO1 functioning in osteoblasts is required for the development of obesity and glucose intolerance in mice.

\section{Discussion}

The results presented in this study reveal what we believe to be a novel site of action for FoxO1. Indeed, this transcription factor acts in osteoblasts to regulate glucose homeostasis. In its metabolic function, FoxO1 integrates signals originating from the skeleton and resulting in changes in pancreatic $\beta$ cell mass and function. In contrast to its classical role as a target of insulin signaling in the pancreas and liver, FoxO1 in osteoblasts is a key transcriptional regulator of insulin secretion and sensitivity. The mechanism mediating the metabolic effects of FoxO1 in osteoblasts is bimodal. It involves upregulation of the expression and stimulation of the activity of osteocalcin, an osteoblast-secreted hormone known to favor glucose homeostasis (12). These results expand the spectrum of functions of FoxO1 and promote the role of the skeleton as a regulator of energy metabolism. The finding that a transcription factor that favors bone homeostasis also affects glucose metabolism suggests the existence of a sensitive channel of communication between bone and pancreas utilized to adapt to and deal with either skeletal or metabolic stress.

FoxO1 in osteoblasts regulates glucose homeostasis by controlling the expression and activity of 2 osteoblast-produced proteins. Using genetic experiments, we have delineated the sequence of events that initiate in osteoblasts with FoxO1 deletion and target $\beta$-islets and adipocytes. Removal of 1 osteocalcin allele from Foxo $1_{o b^{-1-}}$ mice reversed the metabolic abnormalities of the FoxO1 deletion in osteoblasts. This observation suggests that osteocalcin could be the effector of FoxO1 in osteoblasts. Indeed, FoxO1 controls osteocalcin availability by a 2 -tiered mechanism. It suppresses osteocalcin expression by directly binding to its promoter and inhibits osteocalcin bioactivity by promoting $\gamma$-carboxylation. In turn, uncarboxylated rather than carboxylated osteocalcin has been proposed as a mediator of the metabolic actions of osteoblasts (12). Indeed, removal of 1 Esp allele from $\mathrm{Foxo}_{o b}{ }^{+/-}$mice decreases osteocalcin carboxylation and improves glucose handling and insulin sensitivity. Our results suggest that FoxO1 suppresses osteocalcin bioactivity by stimulating the expression of Esp. A reduction in osteocalcin expression concomitant with increased osteocalcin carboxylation leads to insulin resistance, glucose intolerance, and adiposity.

FoxO-to-FoxO signaling from the skeleton to the pancreas. Foxo1 deletion in osteoblasts increases insulin production and stimulates insulin signaling in the pancreas. Remarkably, insulin signaling favors glucose handling by inactivating FoxO1 in the pancreas and liver. Thus, it appears that FoxO1 levels in bone regulate FoxO1 activity in the pancreas or liver. To our knowledge, this is the first demonstration in mammals that FoxO1-to-FoxO1 signaling occurs between different tissues. This model of FoxO1 signaling has been demonstrated in Caenorhabditis elegans, where it occurs via feedback regulation of insulin-like gene expression (34-36). In our studies, FoxO1 signaling is coordinated between bone and pancreas through positive feedback regulation of OST-PTP and osteocalcin. It is possible that other mechanisms, perhaps involving insulin-like peptides, may also be involved. In any case, in a manner equivalent to what has been proposed for C. elegans, a positive feedback signal such as the one described here is likely to bring the rate of metabolic activity between skeleton and pancreas into alignment. 
FoxO1 regulates the crosstalk between bone and pancreas. Why would a transcription factor that is the major target of insulin signaling and mediator of insulin's effects on pancreatic and hepatic glucose metabolism reproduce the same functions through its expression in bone? It is now increasingly appreciated that abnormal glucose, lipid, and bone metabolism, as well as atherosclerosis and neuronal degeneration, share similar molecular pathogenetic mechanisms implicated in the development of these conditions. This is largely due to the fact that the same genes have a similar function in different organs (37). Specifically for FoxO1, extensive research in C. elegans has demonstrated potent evolutionary conservation of FoxO1 transcriptional functions that are shared by different tissues $(34,35)$. These functions coordinate the rate of aging between different tissues. It is possible that mechanisms of FoxO1 action have emerged to preserve and elicit the same metabolic effect through different organs, such as bone and pancreas. Perhaps, in this case also, FoxO1 acts in its most well-described role, namely that of a lifespan extender under metabolic stress (38-41). Under conditions where both the skeleton and glucose handling are deteriorating, such as in aging, FoxO1 may confer a rescuing signal of energy supply from the wasting skeleton to the energy-demanding organs that control glucose metabolism.

Physiological and clinical relevance of the FoxO1-mediated interactions between bone and pancreas. In multiple species including C. elegans, Drosophila melanogaster, and mammals, insulin signaling suppresses the activity of FoxO1. We have found that oxidative stress stimulates FoxO1 activity and that FoxO1 is required for redox balance in osteoblasts and for normal osteoblast proliferation (M.-T. Rached et al., unpublished observations). What do these observations mean for the role of osteoblast-expressed FoxO1 in normal physiology? Although our results are very preliminary, we are tempted to propose that FoxO1 in osteoblasts might serve as a rescue mechanism to reduce the effects of oxidative stress on metabolism. In addition, in the context of metabolic stress (e.g., starvation), reduced insulin levels would lead to an increase in FoxO1 activity in bone. In turn, our findings suggest that this increase in FoxO1 activity in bone would raise blood glucose levels, providing a source of nutrients to the brain. Thus, along with the pancreas and liver, bone may be another organ that supplies energy under stress. Similarly, under conditions of increased oxidative stress, an increase in FoxO1 activity in bone maintains osteoblast numbers and preserves their function as endocrine cells that favor glucose availability.

A growing body of evidence suggests a link between skeletal diseases and glucose metabolism. In mice, in addition to FoxO1, ATF4 is another bone-derived transcription factor that regulates glucose metabolism (42). Remarkably, ATF4 transcriptional activity is decreased and bone formation is hampered in a mouse model of Coffin-Lowry syndrome (43), a rare skeletal dysplasia disease. In humans, abnormalities in glucose metabolism occur when osteocalcin levels are decreased or when osteocalcin is poorly carboxylated, strongly suggesting that this molecule has the same function in humans as in mice (44-47). The inverse relationship between osteocalcin and glucose levels has since been further supported in studies of men and postmenopausal women with type 2 diabetes mellitus $(48,49)$. Collectively, these observations suggest that by identifying bone as an endocrine organ, it is now possible to consider targeted therapeutic strategies to regulate glucose metabolism by modulating the activity or production of individual, bone-specific proteins.

\section{Methods}

Generation of mice. Foxo $1_{0 b} b^{-1-}$ mice were generated by crossing collagen-Cre mice and Foxo1 $1^{f / f l}$ mice that have been previously described $(13,50)$. The WT, null, and Foxo $1^{f l}$ alleles were detected using PCR with primers $5^{\prime}$ GCTTAGAGCAGAGATGTTCTCACATT-3', 5'-CCAGAGTCTTTGTATCAGGCAAATAA-3', and 5'-CAAGTCCATTAATTCAGCACATTGA-3'. Esp- and osteocalcin-knockout mice were described previously (12). Genotyping was performed when mice were 3 weeks of age by PCR analysis of genomic DNA. For all experiments, littermates used as WT control animals were animals homozygous for the floxed Foxo1 allele (Foxo1 $1^{f / f l}$ ). In a separate GTT, we confirmed that the lack of any metabolic phenotype in floxed Foxo1 mice was identical to that of collagen-Cre mice as well as mice with intact alleles $(+/+)$. In all experiments, data presented were obtained from male animals. However, all experiments were reproduced with female mice. All procedures were approved by the Columbia University Institutional Animal Care and Use Committee.

Histological analysis of pancreatic islets, white adipose tissue, and liver sections. Fat and pancreata were collected, fixed overnight in $10 \%$ neutral formalin solution, embedded in paraffin, sectioned at $4 \mu \mathrm{m}$, and stained with H\&E. Pancreatic sections were immunostained for $\beta$ and $\alpha$ cells using guinea pig anti-swine insulin polyclonal antibody and rabbit anti-glucagon polyclonal antibody, respectively (Dako). $\beta$ Cell proliferation was assessed using an antibody recognizing Ki67 antigen, the prototypic cell cycle-related nuclear protein expressed by proliferating cells in all phases of the active cell cycle. Pancreatic sections were deparaffinized in xylene, quenched in $3 \% \mathrm{H}_{2} \mathrm{O}_{2} / \mathrm{H}_{2} \mathrm{O}$ for 5 minutes. Antigens were retrieved by boiling in citrate buffer ( $\mathrm{pH}$ 6.0) for 12 minutes. Sections were then blocked in $5 \%$ goat serum/PBS for 30 minutes and incubated with the primary rabbit polyclonal antibody (1:500; Vector Laboratories) overnight at $4{ }^{\circ} \mathrm{C}$. Sections were developed using 3,3'-diaminobenzidine (DAB) and counterstained with hematoxylin. To evaluate cell sizes or numbers, 4-10 sections (each $15 \mu \mathrm{m}$ apart) were analyzed using a $40 \times$ objective on a Leica microscope outfitted with a CCD camera (Sony) and an OsteoMeasure Analysis System (OsteoMetrics). $\beta$ Cell area represents the surface positive for insulin immunostaining divided by the total pancreatic surface. $\beta$ Cell mass was calculated as $\beta$ cell area multiplied by pancreatic weight. At least 4 mice were analyzed per condition. Livers were cryoembedded, sectioned at $5 \mu \mathrm{m}$, and stained with oil red $\mathrm{O}$ (Crystalgen).

Transient transfections and luciferase assays. Cos-7 cells were seeded in 48-well plates at a density of $10^{4}$ cells/well. One day after plating, cells were transfected with Lipofectamine 2000 (Invitrogen) according to the manufacturer's protocol. We carried out cotransfections of the FoxO1 expression plasmid with either an Esp reporter construct or an osteocalcin reporter construct (50 ng). The total amount of DNA was adjusted to $270 \mathrm{ng} /$ well with pCMV5 or pcDNA control vectors. Transfection was stopped by addition of $20 \%$ FBS. Luciferase assays were carried out using the Dual Luciferase Reporter Assay System (Promega), and luciferase activity was quantified using Fluostar Omega (BMG Labtech Inc.). pRL-CMV Renilla luciferase control vector (20 ng; Promega) was cotransfected as an internal standard to normalize for transfection efficiency. Normalized luciferase activity is presented as fold induction over the empty vector control (EV, considered 1). All experiments were repeated at least twice.

Cell cultures. For coculture experiments, islets were isolated using Histopaque 1077 density centrifugation (Sigma-Aldrich). In brief, after clamping the common bile duct at its entrance to the duodenum, $1 \mathrm{mg} / \mathrm{ml}$ collagenase P in M199 medium was injected into the duct. The swollen pancreas was surgically removed and incubated at $37^{\circ} \mathrm{C}$ for 15 minutes. Digested pancreata were dispersed by pipetting, rinsed twice, filtered through a Spectra mesh (Small Parts Inc.) $(400 \mu \mathrm{m})$, resuspended in Histopaque, and overlaid with M199 medium. Islets were collected following centrifugation 
at $1,700 \mathrm{~g}$ for 20 minutes with no brake, washed twice with cold M199 medium, resuspended in $\mathrm{M} 199 / 1 \% \mathrm{FCS}$, and cultured at $37^{\circ} \mathrm{C}$ in $5 \% \mathrm{CO}_{2}$. Primary osteoblasts were prepared from calvaria of 5-day-old pups as previously described (51) and were cultured in fresh $\alpha \mathrm{MEM}$ and $10 \% \mathrm{FBS}$ in the presence of $100 \mu \mathrm{g} / \mathrm{ml}$ ascorbic acid and $5 \mathrm{mM} \beta$-glycerophosphate for 5 days. Twenty-four hours before addition of primary islets, osteoblasts were placed in $\alpha \mathrm{MEM} / 1 \% \mathrm{FBS}$. After 4 hours of coculture, islets were collected for RNA isolation using TRIzoL (Invitrogen).

Real-time quantitative PCR analysis. Bone, liver, white fat, brown fat, gastrocnemius skeletal muscle, gut, pancreas, brain stem tissues, primary osteoblasts, and islet cells were homogenized, and total RNA was isolated using TRIzol reagent. Bone marrow cells were removed from bones by flushing the femurs or tibia with PBS. Total RNA $(2 \mu \mathrm{g})$ was treated with DNAse I (Invitrogen) and reverse transcribed at $42^{\circ} \mathrm{C}$ with SuperScript II (Invitrogen). The expression of all the genes was measured by real-time quantitative PCR with the SYBR Green Master Mix (Bio-Rad) using $18 \mathrm{~S}$ as endogenous control with 1 cycle at $95^{\circ} \mathrm{C}$ for 10 minutes followed by 40 cycles at $95^{\circ} \mathrm{C}$ for 30 seconds and $60^{\circ} \mathrm{C}$ for 1 minute.

Immunoblotting. Calvaria cell extracts $(50 \mu \mathrm{g})$ from WT and $\mathrm{Foxo}_{o b^{-/-}}$mice were analyzed on an SDS-polyacrylamide gel, transferred to a PVDF membrane, and probed with FoxO1 primary antibody (rabbit polyclonal; Santa Cruz Biotechnology Inc.). Mitochondrial DNA protein complexes were detected with Rodent Total OXPHOS Complexes Detection Kit cocktail of antibodies (MitoSciences).

Metabolic studies. IPGTT was performed by administering $2 \mathrm{~g}$ of glucose per kg BW i.p. after an overnight fast. For parallel experiments of IPGTT and OGTT, 1.5 g glucose were administered per kg BW either i.p. or orally by gavage after an overnight fast $(22,23)$. Blood glucose was monitored using blood glucose strips (Diabetes Association) and the Accu-Check glucometer. For pyruvate tolerance tests (PTTs), mice were fasted 18 hours and injected i.p. with $2 \mathrm{~g} / \mathrm{kg} \mathrm{BW}$ of sodium pyruvate (Sigma-Aldrich). Blood was collected from tails. For glucose-stimulated insulin secretion test (GSIS), $3 \mathrm{~g} / \mathrm{kg} \mathrm{BW}$ of glucose was injected i.p. after an overnight fast; plasma was collected from tails using heparinized microcapillaries and insulin measured at $0,2,5,15$, and 30 minutes. For ITT, mice were fasted from 4 to 6 hours and injected i.p. with insulin $(0.5 \mathrm{U} / \mathrm{kg} \mathrm{BW})$, and blood glucose levels were measured at indicated times. ITT data are presented as percentage of initial blood glucose concentration. Hyperinsulinemic-euglycemic clamps were performed at the UMass Mouse Metabolic Phenotyping Center. Briefly, Foxo $1_{o b}{ }^{-1-}$ mice and WT littermates ( $n=5$ for each group) were fasted overnight, and a 2-hour hyperinsulinemic ( $2.5 \mathrm{mU} / \mathrm{kg} / \mathrm{min})$ euglycemic clamps were performed following intravenous administration of $\left[3-{ }^{3} \mathrm{H}\right]$ glucose and 2-deoxy-D-[ $\left[1-{ }^{14} \mathrm{C}\right]$ glucose as previously described $(52)$. HFD (Research Diets) contained 58\% fat.

Physiological assays. For insulin, adiponectin, leptin, and osteocalcin measurements, sera were collected by heart puncture from mice in the fed and fasted states. Insulin (Mercodia), adiponectin (Millipore), and leptin (Crystal Chem) levels were measured by ELISA. Glucagon levels were measured by radioimmunoassay (Millipore). Growth hormone levels were measured by ELISA (Diagnostic System Laboratories Inc.). Blood was kept on ice for 15 minutes before centrifugation for 15 minutes, at maximum speed. For quantification of uncarboxylated levels of osteocalcin, sera were incubated with hydroxyapatite slurry for 1 hour. The quantity of osteocalcin present in the unbound fraction (uncarboxylated) and in the fractions eluted at 0.02 and $1 \mathrm{M}$ sodium phosphate (undercarboxylated), pH 6.8, was measured by an IRMA assay (Immunotopics) as described previously (12).

ChIP assay. ChIP assays were performed as per the manufacturer's instructions (Upstate Biotechnology) using primary osteoblasts. PCR primers were designed to span FoxO1-binding sites in the promoter and the first intron of the osteocalcin and the Esp genes; primers spanning FoxO1 consensus sites in the fourth exon of each gene were used as a negative control. Esp was measured using an Esp reporter construct that carries 722 bp of the promoter region and $1,095 \mathrm{bp}$ of the first intron and exon of the gene (region -722 to $+1,095$ ) (Figure 7E). This region of Esp was selected because it contains 2 putative FoxO1-binding sites, present at positions $+137 \mathrm{bp}$ (TGTTTTT) and $+947 \mathrm{bp}$ (TGTTTTT) of the first intron of the gene. We used FoxO1 (H-128) antibody (Santa Cruz Biotechnology Inc.).

Adenine nucleotide levels measurement by HPLC. To determine the adenine nucleotide concentrations, mice were sacrificed and the vastus lateralis skeletal muscle was rapidly extracted and frozen in liquid nitrogen. Fifty milligrams of tissue was homogenized in $500 \mathrm{ml}$ of ice-cold PBS containing $0.5 \mathrm{M}$ perchloric acid and centrifuged at $16,000 \mathrm{~g}$ for 10 minutes at $4^{\circ} \mathrm{C}$. The pellets were stored at $-80^{\circ} \mathrm{C}$ for protein measurement, and adenine nucleotides were measured in the resultant supernatants into an Alliance HPLC (Waters Corp.) with an Alltima C18NUC reverse-phase column (Alltech Associates) (53). After stabilizing the column with the mobile phase, samples $(50 \mathrm{ml})$ were injected onto the HPLC system. The mobile phase consisted of $0.2 \mathrm{M}$ ammonium phosphate buffer, $\mathrm{pH} 3.5$ (phase A) and $30 \%$ methanol in $0.2 \mathrm{M}$ ammonium phosphate buffer, $\mathrm{pH} 3.5$ (phase B). Standard curves for AMP, ADP, and ATP were constructed with 15, 30, and $60 \mathrm{mM}$ of each nucleotide. Absorbance of the samples was measured with a UV detector at $260 \mathrm{~nm}$ wavelength, and the concentration of each nucleotide in the samples was calculated based on the peak area. Adenine nucleotide levels were expressed in $\mathrm{nmol} / \mathrm{mg}$ protein (53).

Energy balance. Energy expenditure was measured by indirect calorimetric method using a 6-chamber Oxymax system (Columbus Instruments). Mice were acclimatized for 24 hours before measurements were taken every 14 minutes for 48 hours. Body composition was measured with NMR (Bruker Optics). For food intake studies, mice were individually housed in metabolic cages (Nalgene) and fed ad libitum. The amount of food consumption was determined by weighing the powdered chow before and after the 24-hour measurement.

Statistics. Results are given as mean \pm SEM. Statistical analyses were performed using unpaired 2-tailed Student's $t$ test or a 1-way ANOVA (Student-Newman-Keuls) for more than 2 groups. A $P$ value of less than 0.05 was considered significant.

\section{Acknowledgments}

The authors are grateful to John P. Bilezikian, Domenico Accili, and Anthony Ferrante for helpful discussions; Eiichi Hinoi for helpful suggestions on osteocalcin carboxylation assays; Luis Garcia for help in the HPLC measurements; Chiyuan A. Zhang for help with the statistical analysis; and Charles Duncan for technical assistance. We are grateful to the histology facility of the Diabetes and Endocrinology Research Center (DERC) of Columbia University Medical Center (supported by NIDDK DK06360807) for help with histological analysis. This work was supported by NIH grants AR055931 and AR054447 (to S. Kousteni) and AR045548 and DK078042 (to G. Karsenty) and grants from the Brazilian National Council of Technological and Scientific Development (to B.C. Silva).

Received for publication May 19, 2009, and accepted in revised form October 14, 2009.

Address correspondence to: Stavroula Kousteni, The Russ Berrie Medical Sciences Pavilion, 1150 Saint Nicholas Avenue, Room 312, New York, New York 10032, USA. Phone: (212) 851-5223; Fax: (212) 851-5225; E-mail: sk2836@columbia.edu. 
1. Accili D. Lilly lecture 2003: the struggle for mastery in insulin action: from triumvirate to republic. Diabetes. 2004;53(7):1633-1642.

2. Ebina $Y$, et al. The human insulin receptor cDNA: the structural basis for hormone-activated transmembrane signalling. Cell. 1985;40(4):747-758

3. Accili D, Arden KC. FoxOs at the crossroads of cellular metabolism, differentiation, and transformation. Cell. 2004;117(4):421-426.

4. Nakae J, et al. Regulation of insulin action and pancreatic beta-cell function by mutated alleles of the gene encoding forkhead transcription factor Foxo1. Nat Genet. 2002;32(2):245-253.

5. Matsumoto M, Pocai A, Rossetti L, DePinho RA, Accili D. Impaired regulation of hepatic glucose production in mice lacking the forkhead transcription factor Foxo 1 in liver. Cell Metab. 2007;6(3):208-216

6. Puigserver $\mathrm{P}$, et al. Insulin-regulated hepatic gluconeogenesis through FOXO1-PGC-1alpha interaction. Nature. 2003;423(6939):550-555.

7. Nakae J, et al. The forkhead transcription factor Foxo 1 regulates adipocyte differentiation. Dev Cell. 2003;4(1):119-129.

8. Hribal ML, Nakae J, Kitamura T, Shutter JR, Accili D. Regulation of insulin-like growth factor-dependent myoblast differentiation by Foxo forkhead transcription factors. J Cell Biol. 2003;162(4):535-541.

9. Kitamura YI, et al. FoxO1 protects against pancreatic beta cell failure through NeuroD and MafA induction. Cell Metab. 2005;2(3):153-163.

10. Kitamura T, et al. The forkhead transcription factor Foxo1 links insulin signaling to $\mathrm{Pdx} 1$ regulation of pancreatic beta cell growth. J Clin Invest. 2002;110(12):1839-1847.

11. Hashimoto $\mathrm{N}$, et al. Ablation of PDK1 in pancreatic beta cells induces diabetes as a result of loss of beta cell mass. Nat Genet. 2006;38(5):589-593.

12. Lee NK, et al. Endocrine regulation of energy metabolism by the skeleton. Cell. 2007;130(3):456-469.

13. Paik JH, et al. FoxOs are lineage-restricted redundant tumor suppressors and regulate endothelial cell homeostasis. Cell. 2007;128(2):309-323.

14. Bogdanovic $Z$, et al. Upstream regulatory elements necessary for expression of the rat COL1A1 promoter in transgenic mice. J Bone Miner Res. 1994;9(2):285-292.

15. Schwartzberg PL, et al. Rescue of osteoclast function by transgenic expression of kinasedeficient $\mathrm{Src}$ in $\mathrm{src}^{-/-}$mutant mice. Genes Dev. 1997;11(21):2835-2844.

16. Hentunen TA, et al. Immortalization of osteoclast precursors by targeting $b c l-X_{L}$ and Simian Virus 40 large $\mathrm{T}$ antigen to the osteoclast lineage in transgenic mice. J Clin Invest. 1998;102(1):88-97.

17. Chiu WS, et al. Transgenic mice that express Cre recombinase in osteoclasts. Genesis. 2004;39(3):178-185.

18. Lovshin JA, Drucker DJ. Incretin-based therapies for type 2 diabetes mellitus. Nat Rev Endocrinol. 2009;5(5):262-269.

19. Baggio LL, Drucker DJ. Biology of incretins: GLP-1 and GIP. Gastroenterology. 2007;132(6):2131-2157.

20. Fujita $Y$, et al. Incretin release from gut is acutely enhanced by sugar but not by sweeteners in vivo. Am J Physiol Endocrinol Metab. 2009;296(3):E473-E479.

21. Wideman RD, Kieffer TJ. Mining incretin hormone pathways for novel therapies. Trends Endocrinol Metab. 2009;20(6):280-286.

22. Hansotia $T$, et al. Extrapancreatic incretin receptors modulate glucose homeostasis, body weight, and energy expenditure. J Clin Invest. 2007;117(1):143-152.

23. Lamont BJ, Drucker DJ. Differential antidiabetic efficacy of incretin agonists versus DPP-4 inhibition in high fat fed mice. Diabetes. 2008;57(1):190-198.

24. Moller N, Jorgensen JO. Effects of growth hormone on glucose, lipid, and protein metabolism in human subjects. Endocr Rev. 2009;30(2):152-177.

25. Kitamura T, et al. Forkhead protein FoxO1 mediates Agrp-dependent effects of leptin on food intake. Nat Med. 2006;12(5):534-540.

26. Yang G, et al. FoxO1 inhibits leptin regulation of pro-opiomelanocortin promoter activity by blocking STAT3 interaction with specificity protein 1 . J Biol Chem. 2009;284(6):3719-3727.

27. Narkar VA, et al. AMPK and PPARdelta agonists are exercise mimetics. Cell. 2008;134(3):405-415.

28. Yamauchi $\mathrm{T}$, et al. The fat-derived hormone adiponectin reverses insulin resistance associated with both lipoatrophy and obesity. Nat Med. 2001;7(8):941-946.

29. Steppan CM, et al. The hormone resistin links obesity to diabetes. Nature. 2001;409(6818):307-312.

30. Friedman JM, Halaas JL. Leptin and the regulation of body weight in mammals. Nature. 1998;395(6704):763-770

31. Ferron M, Hinoi E, Karsenty G, Ducy P. Osteocalcin differentially regulates beta cell and adipocyte gene expression and affects the development of metabolic diseases in wild-type mice. Proc Natl Acad Sci US A. 2008;105(13):5266-5270.

32. Hinoi $\mathrm{E}$, et al. The sympathetic tone mediates leptin's inhibition of insulin secretion by modulating osteocalcin bioactivity. J Cell Biol. 2008;183(7):1235-1242.

33. Ducy P, Zhang R, Geoffroy V, Ridall AL, Karsenty G. Osf2/Cbfa1: a transcriptional activator of osteoblast differentiation. Cell. 1997;89(5):747-754.

34. Murphy CT, et al. Genes that act downstream of DAF-16 to influence the lifespan of Caenorhabditis elegans. Nature. 2003;424(6946):277-283.

35. Murphy CT, Lee SJ, Kenyon C. Tissue entrainment by feedback regulation of insulin gene expression in the endoderm of Caenorhabditis elegans. Proc Natl Acad Sci U S A. 2007;104(48):19046-19050.

36. McElwee J, Bubb K, Thomas JH. Transcriptional outputs of the Caenorhabditis elegans forkhead protein DAF-16. Aging Cell. 2003;2(2):111-121.

37. Mani A, et al. LRP6 mutation in a family with early coronary disease and metabolic risk factors. Science. 2007;315(5816):1278-1282.

38. Martin FM, Friedman JS. Ticking fast or ticking slow, through Shc must you go? Sci Aging Knowledge Environ. 2004;2004(32):pe32.

39. Trinei $M$, et al. A p53-p66Shc signalling pathway controls intracellular redox status, levels of oxidation-damaged DNA and oxidative stress-induced apoptosis. Oncogene. 2002;21(24):3872-3878.

40. Nemoto S, Finkel T. Redox regulation of forkhead proteins through a p66shc-dependent signaling pathway. Science. 2002;295(5564):2450-2452.

41. Tothova $Z$, et al. FoxOs are critical mediators of hematopoietic stem cell resistance to physiologic oxidative stress. Cell. 2007;128(2):325-339.

42. Yoshizawa T, et al. The transcription factor ATF4 regulates glucose metabolism through its expression in osteoblasts. J. Clin. Invest. 2009;119(9):2807-2817.

43. Yang $X$, et al. ATF4 is a substrate of RSK2 and an essential regulator of osteoblast biology; implication for Coffin-Lowry syndrome. Cell. 2004;117(3):387-398

44. Berkner KL. The vitamin K-dependent carboxylase. Annu Rev Nutr. 2005;25:127-149.

45. Rosato MT, Schneider SH, Shapses SA. Bone turnover and insulin-like growth factor I levels increase after improved glycemic control in noninsulin-dependent diabetes mellitus. Calcif Tissue Int. 1998;63(2):107-111.

46. Obrant KJ, et al. The proportion of carboxylated to total or intact osteocalcin in serum discriminates warfarin-treated patients from control subjects. J Bone Miner Res. 1999;14(4):555-560.

47. Sayinalp S, Gedik O, Koray Z. Increasing serum osteocalcin after glycemic control in diabetic men. Calcif Tissue Int. 1995;57(6):422-425.

48. Kanazawa I, et al. Serum osteocalcin level is associated with glucose metabolism and atherosclerosis parameters in type 2 diabetes mellitus. J Clin Endocrinol Metab. 2009;94(1):45-49.

49. Krakauer JC, et al. Bone loss and bone turnover in diabetes. Diabetes. 1995;44(7):775-782.

50. Dacquin R, Starbuck M, Schinke T, Karsenty G. Mouse alpha1(I)-collagen promoter is the best known promoter to drive efficient Cre recombinase expression in osteoblast. Dev Dyn. 2002;224(2):245-251.

51 . Kousteni $S$, et al. Induction of osteoblast differentiation by selective activation of kinase-mediated actions of the estrogen receptor. Mol Cell Biol. 2007;27(4):1516-1530.

52. Kim HJ, et al. Differential effects of interleukin-6 and -10 on skeletal muscle and liver insulin action in vivo. Diabetes. 2004;53(4):1060-1067.

53. Akman HO, et al. Thymidine kinase 2 (H126N) knockin mice show the essential role of balanced deoxynucleotide pools for mitochondrial DNA maintenance. Hum Mol Genet. 2008;17(16):2433-2440. 